\title{
F-perceptory: an approach for handling fuzziness of spatiotemporal data in geographical databases
}

\author{
Asma Zoghlami* \\ LIASD, University of Paris 8, \\ 2, Rue de la Liberté, \\ 93526 Saint-Denis Cedex, France \\ Email: zoghlami@ai.univ-paris8.fr \\ *Corresponding author

\section{Cyril de Runz}

CReSTIC, University of Reims Champagne-Ardenne,

Chemin des Rouliers CS30012,

51687 Reims Cedex 2, France

Email: cyril.de-runz@univ-reims.fr

\section{Herman Akdag}

LIASD, University of Paris 8,

2, Rue de la Liberté,

93526 Saint-Denis Cedex, France

Email: herman.akdag@ai.univ-paris8.fr

\begin{abstract}
In the literature, several studies have focused on introducing fuzzy extensions to the relational and/or object database models in order to store the imprecision. Indeed, on one hand, fuzzy EER and fuzzy UML are both applied for fuzzy object-oriented database modelling. On the other hand, Fuzzy ER is adapted for fuzzy relational database models. All these previous fuzzy conceptual modelling methods are not adapted to fuzzy spatiotemporal data. In this paper, we propose an approach for modelling imprecise data in object and relational databases based on the representation of data using connected and normalised fuzzy sets stored via $\alpha$-cuts. The approach is applied to geographical information systems in order to handle imprecise spatiotemporal data.
\end{abstract}

Keywords: imprecise data; fuzzy set; geographical information system; GIS; spatiotemporal data; unified modelling language; UML.

Reference to this paper should be made as follows: Zoghlami, A., de Runz, C. and Akdag, H. (2016) 'F-perceptory: an approach for handling fuzziness of spatiotemporal data in geographical databases', Int. J. Spatial, Temporal and Multimedia Information Systems, Vol. 1, No. 1, pp.30-62.

Biographical notes: Asma Zoghlami received her $\mathrm{PhD}$ in Computer Science from the University Paris 8 (France) in 2013. She works at the computer science lab LIASD. Her research topic is the management of imprecise data in geographic information system. 
Cyril de Runz received his PhD in Computer Science from the University of Reims Champagne Ardenne (France) in 2008. As an Associate Professor at the same university, he works at the computer science lab CReSTIC and at the LIASD (University Paris 8, France) as an associate member. His research interests span imperfection in geographic and archaeological information, spatio-temporal data modelling and representation and spatio-temporal data mining.

Herman Akdag is currently a Full Professor of Computer Science at Paris-Lumières University. He was also a Senior Researcher in the LIP6 laboratory (Laboratoire d'Informatique de Paris VI) with the MaLIRE team. Initially focused on information theory and knowledge representation, his scientific orientations evolved to machine learning and cognitive modelling via fuzzy logic. He is also an active researcher in the areas of approximate reasoning, fuzzy set theory, decision-making methods, image retrieval, fuzzy abduction, data mining, robotics and user modelling. From 1980 to 2011, he was an Associate Professor, then Full Professor at Champagne-Ardennes University. A former head of Modeco Research Group and the Research Master RACOR in Champagne-Ardennes University, he is actually member of LIASD Lab, Head of Professional Master CPI and member of the University Paris-Lumières Senat. He has published more than 140 papers in conference proceedings, journals and books.

This paper is a revised and expanded version of a paper entitled 'Through a fuzzy spatiotemporal information system for handling excavation data' presented at AGILE 2012, Avignon, France, 2012.

\section{Introduction}

The representation of imperfect data and its exploitation in information systems is a major theme of the artificial intelligence domain (Sapir et al., 2008; Druzdzel, 1996; Yang et al., 2009). Thus, several studies have focused on proposing new conceptual data modelling approaches to store imperfect information and to establish fuzzy queries that consider the data imperfection (Bosc and Pivert, 1995).

Among existing tools for modelling information systems, the unified modelling language (UML) (OMG, 2000) is considered as a standard. However, the data represented in UML models were far from reflecting the real-world situations due to uncertainty, imprecision, etc. To respond to this new requirement, an extension called fuzzy UML (Ma, 2005; Ma and Yan, 2010) has been introduced in order to enable the conceptual modelling of imprecise data. Thus, different levels of imprecision have been mainly introduced into the UML class model. However, as fuzzy UML does not explicitly consider imprecise spatial and temporal data, it is possible but complex to model them. Moreover, fuzzy UML allows constraints for fuzzy sets defined on R but not on $\mathrm{R}^{2}$. Therefore, it is not the easiest way for modelling information in geographical information systems (GIS) that are distinguished by the fact that the data is considered either according to its spatial or temporal component or according to its spatiotemporal component.

In this article, we propose an approach based on connected and normalised fuzzy sets stored via $\alpha$-cuts. It aims to handle imprecise data in relational and object-oriented 
databases. The approach is then applied in a GIS in order to implement a fuzzy spatiotemporal database storing imprecise data. It is based upon the F-perceptory approach, presented in Zoghlami (2013), which is an extension to handle fuzziness in the perceptory data model (Bédard et al., 2004). The latter enriches the UML approach to support the space/time modelling through the PictograF language formerly called plug-in for visual language (PVL).

This article is structured as follows. Section 2 defines the different basic nature of data imperfection and presents the fuzzy set theory. Section 3 highlights the approach that we propose in order to model imprecise information in an object database view and then in a relational database view. Our approach makes the distinction between the fuzzy data case and the possibilistic data case. Thus, we identify the main constraints implemented in both cases. Section 4 presents an application of our approach in the geographic information field aiming to handle imprecise spatiotemporal data. Therefore, we introduce the F-perceptory approach devoted to modelling imprecise spatial and temporal data in the perceptory data model. Section 5 exposes a case study dedicated to construct a fuzzy GIS for the representation and the analysis of archaeological data. Section 6 establishes a discussion in which we first make a comparative study between the main fuzzy conceptual models and F-perceptory and then a second comparative study between the basic spatiotemporal conceptual data models and F-perceptory. The last section (7) is devoted to the conclusion and the perspectives of this work.

\section{Data imprecision and imperfection}

\subsection{Nature of imperfection}

Human reasoning as an information source is often imperfect. The terms commonly used to describe imperfect information are: incomplete, uncertain, imprecise, fuzzy etc. (Smets, 1996). Figure 1 illustrates the three main types of imperfection as presented in Bouchon-Meunier, 1995).

Figure 1 Example of the main imperfection types

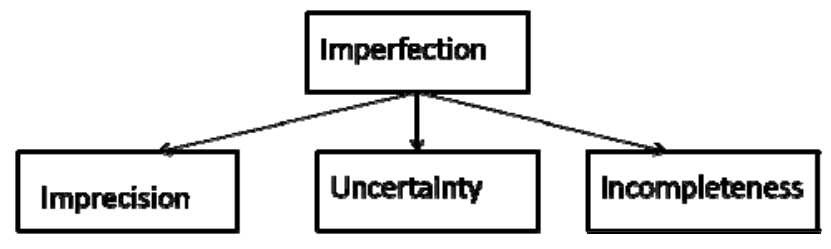

The imprecision raises difficulty in a statement due to not knowing the exact data or to the fact that the natural language terms used to describe a system characterise it in a vague way. The following statement illustrates an example of imprecision: 'the residential building is about $30 \mathrm{~m}$ high'. In this case the possible values are a priori in the interval $(25,35)$.

The uncertainty concerns a doubt on the validity of the knowledge. It is due to the reliability of the observer who is unsure, so he cannot determine the true value of the knowledge. We can illustrate the concept of uncertainty through the following example: 
'what we see seems to be a residential building'. In this case, it may be a residential building or it may not.

The incompleteness is a lack of knowledge or a partial knowledge of some system specifications.

There are various more detailed taxonomies of the imperfection types. The most commonly used in the geographic information community is the one introduced in Fisher et al. (2006) and illustrated in Figure 2. To denote the imperfection, the authors of this model use the term 'uncertainty' as a global concept that includes all the other concepts. They consider that the principal source of uncertainty is the real-world abstraction process, mainly through the definition of classes and the assignment of an object to a class. As shown in Figure 2, the modelling of imperfect data may be done using a lot of theories (probabilities, possibilities, fuzzy sets, etc.). All of them use a paradigm of the attribution of weights [between $(0,1)]$ to each element of the studied domain.

Figure 2 The spatial uncertainty model (see online version for colours)

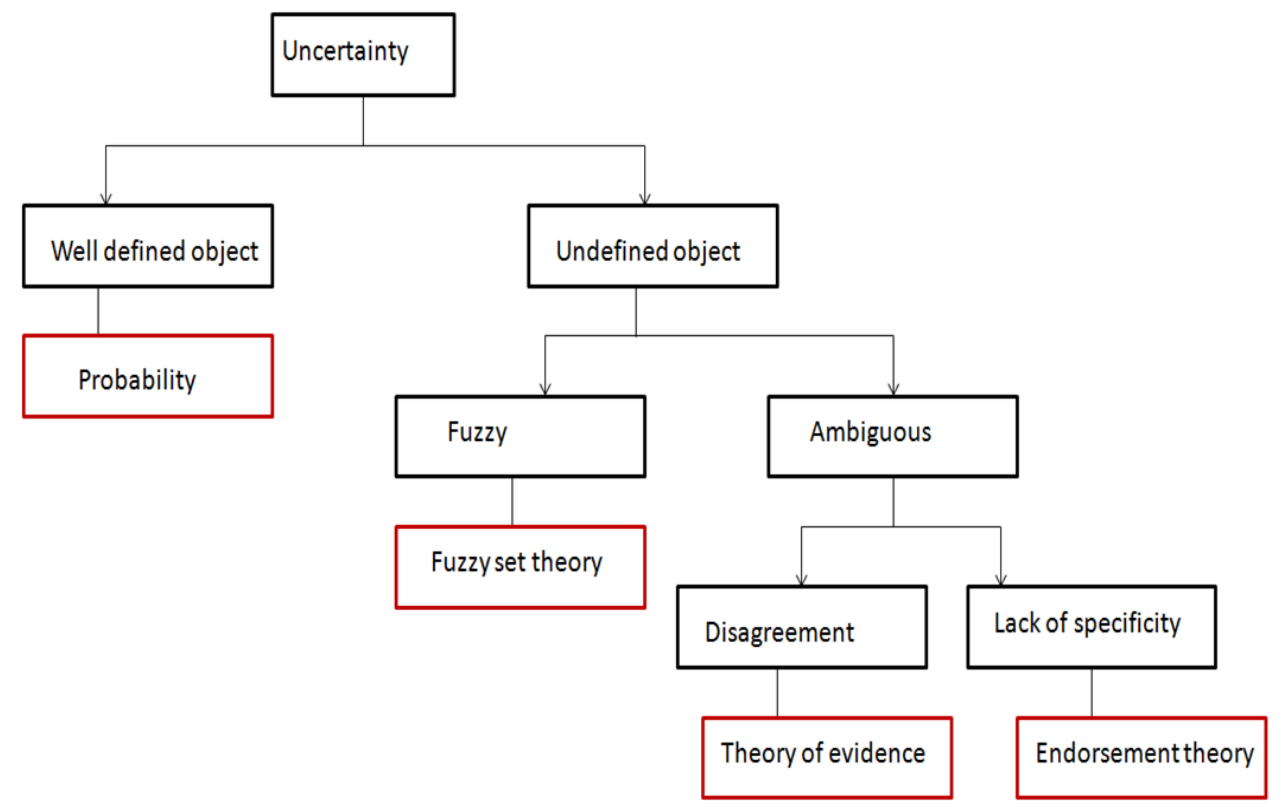

Source: Fisher et al. (2006)

\subsection{Dealing with imprecision: the fuzzy set theory}

Imprecision should be considered in the modelling of the information. As the sorites paradox makes it evident that probabilities are not adapted to imprecision, Zadeh introduced the fuzzy set theory (Zadeh, 1965). Indeed, the fuzzy set theory defines the notion of partial and valued membership of a value to a class. A fuzzy set $A$ is characterised by a membership $\mu \mathrm{A}$ function taking values in $(0,1)$. For each domain value $x$, a membership degree $\mu \mathrm{A}(x)$, defined in $(0,1)$, is proposed. Therefore, concepts like young, old, etc. may be easily modelled by fuzzy sets. 
An $\alpha$-cut A $\alpha$, for all $\alpha>0$, is the set of the domain values (the set of $x$ ) having a membership degree higher or equal to $\alpha(\mu A(x) \geq \alpha)$. By convention, A0 is the set of $x$ such as $\mu \mathrm{A}(x)>0$.

A fuzzy set A is connected if and only if, for all $\alpha$ in $(0 ; 1) A \alpha$ is connected. A $\alpha$ is connected if for all nonempty sets $\mathrm{B}$ and $\mathrm{C}$, such as $\mathrm{A} \alpha$, is their union and there exists at least one point of $\mathrm{B}$ adhering to $\mathrm{C}$ or one point of $\mathrm{C}$ adhering to $\mathrm{B}$. On $\mathrm{R}, \mathrm{A} \alpha$ is connected if and only if, it is an interval. In other words, a fuzzy set $\mathrm{A}$ is connected if and only if, for all $\alpha$ in $[0 ; 1], \mathrm{A} \alpha$ is not composed with separate sets.

\section{Modelling imprecise information}

We distinguish two types of data imprecision. The first type corresponds to the fuzzy object. A fuzzy object corresponds to an object for which we have a core (restrictive) definition and a set of soft (less restrictive) definitions including the more restrictive definitions. The less restrictive definition is: the larger the set of values, the lower the membership degree.

Figure 3 Example of fuzzy data (see online version for colours)

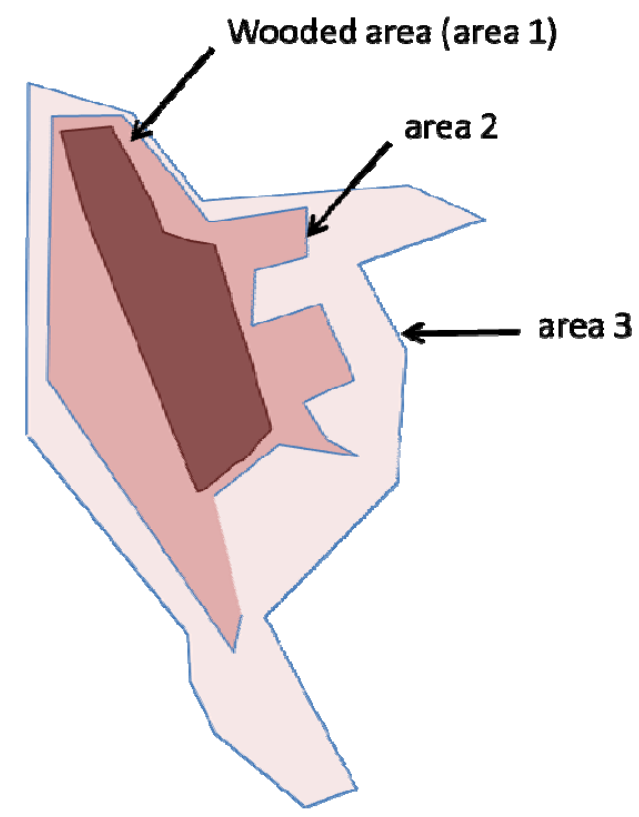

Membership degrees:

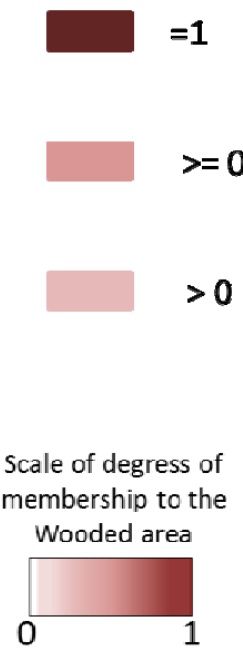

Figure 3 shows an example of fuzzy spatial data relating to the delimitation of a wooded area. In this case, the question that arises is the following: which areas form a part of the wooded area and when can we say that we are no longer in a wooded area?

To answer this question, a representation of the different areas according to a fuzzy model is interesting. This representation involves a scale of degrees of membership to the wooded area between 0 and 1 . Thus, area 1 entirely belongs to the wooded area with a membership degree of 1 . Area 2 belongs to the wooded area with a membership degree 
greater than 0.5 and area 3 belongs to the wooded area with a membership degree greater than 0 .

The second type of imprecision corresponds to the possibilistic object. A possibilistic object is an object for which we have a set of possible definitions (hypotheses) with confidence values (one value for each definition). Those definitions may overlap. If one of them includes another one, the confidence value of the first one does not have to be lower than the second definition confidence value.

Figure 4 Example of possibilistic data (see online version for colours)

\section{Membership degrees :}

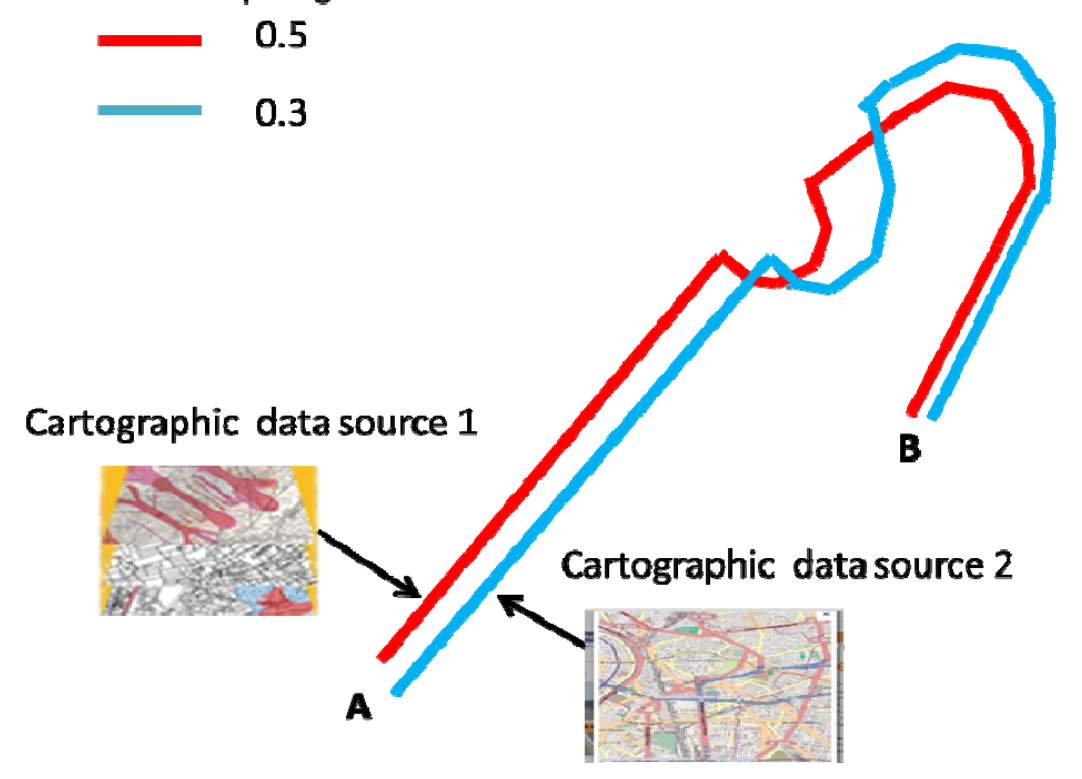

Figure 4 illustrates an example of a possibilistic spatial data corresponding to the value of the distance between two points: A and B. In this case, we retain the two values of the distance obtained according to the two cartographic data sources, by associating to each value a degree of possibility.

\subsection{Modelling fuzzy data}

In this article, we propose an approach based on the use of a set of connected $\alpha$-cuts in order to model and store the imprecision in both object databases and relational databases. Our modelling approach allows us to reduce the cost and the complexity of the storage, to maintain the possibilities of exploitation and to keep at the same time a global view of the fuzzy set. The notion of connection is particularly useful in applications dedicated to classification, optimisation, etc.

In our case, the use of connected $\alpha$-cuts allows us to store different values of the imprecise data in the form of a multi-valued set. Their use enables us to draw the boundaries between a very low confidence membership (the 0-cut), a rather low confidence membership, a moderately low confidence membership, a low confidence 
membership, etc. which may also be interpreted as a range of values between almost impossible and very possible (Figure 5).

Figure 5 Interpretation examples on connected $\alpha$-cuts (see online version for colours)

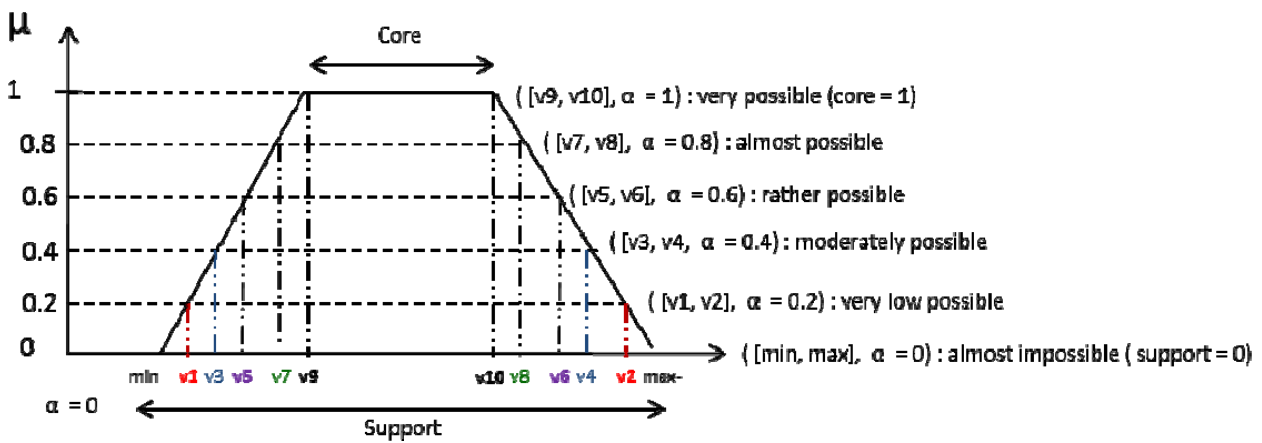

\subsubsection{Object view}

We can model the fuzzy object according to the representation proposed in Figure 6. In this figure, the fuzzy object is composed of $n$ objects belonging to the class 'fuzzy object imprecision' where $n$ is the chosen number of $\alpha$-cuts and the 'fuzzy object imprecision' class is devoted to store the fuzzy information as a multivalent set of values (Akdag et al., 1992). In fact, each fuzzy set referenced in the latter class is characterised by its identifier (fuzzy set-id), the different values of its $\mathrm{n} \alpha$-cuts ( $\alpha$-value), the minimum value and the maximum value of each $\alpha$-cut (min-level and max-level).

Figure 6 A fuzzy object representation in an object database view

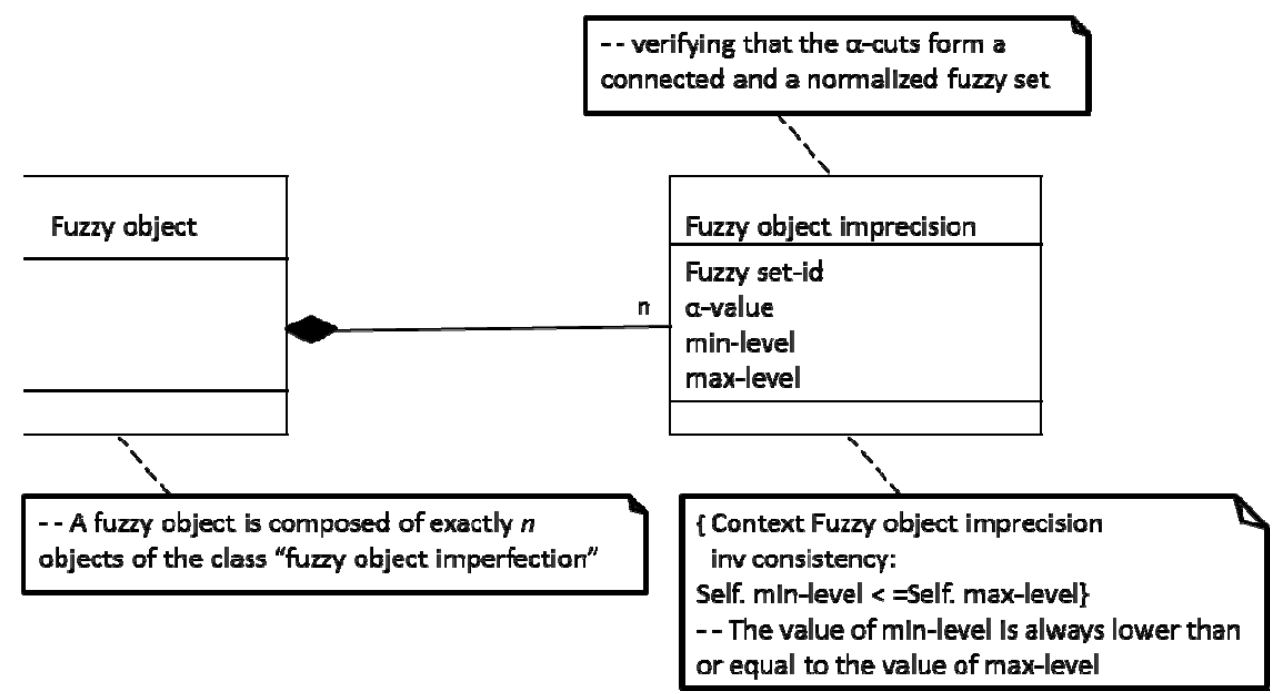

In this case, we check three constraints. The first constraint is to ensure that the value of the min-level is always lower than or equal to the value of the max-level. The second constraint consists in verifying that the set of $\alpha$-cuts form a connected and normalised 
fuzzy set. The third constraint is to ensure that a fuzzy object is composed of exactly $n$ objects belonging to the class 'fuzzy object imprecision'.

In Figure 7, we represent an example of a fuzzy object corresponding to a stone rate in a wall as an expert can describe. In this example, the stone rate is represented by a fuzzy set described by four alpha cuts which respectively correspond to the values $0,0.4$, 0.8 and 1.

Figure 7 A fuzzy object example represented in an object diagram

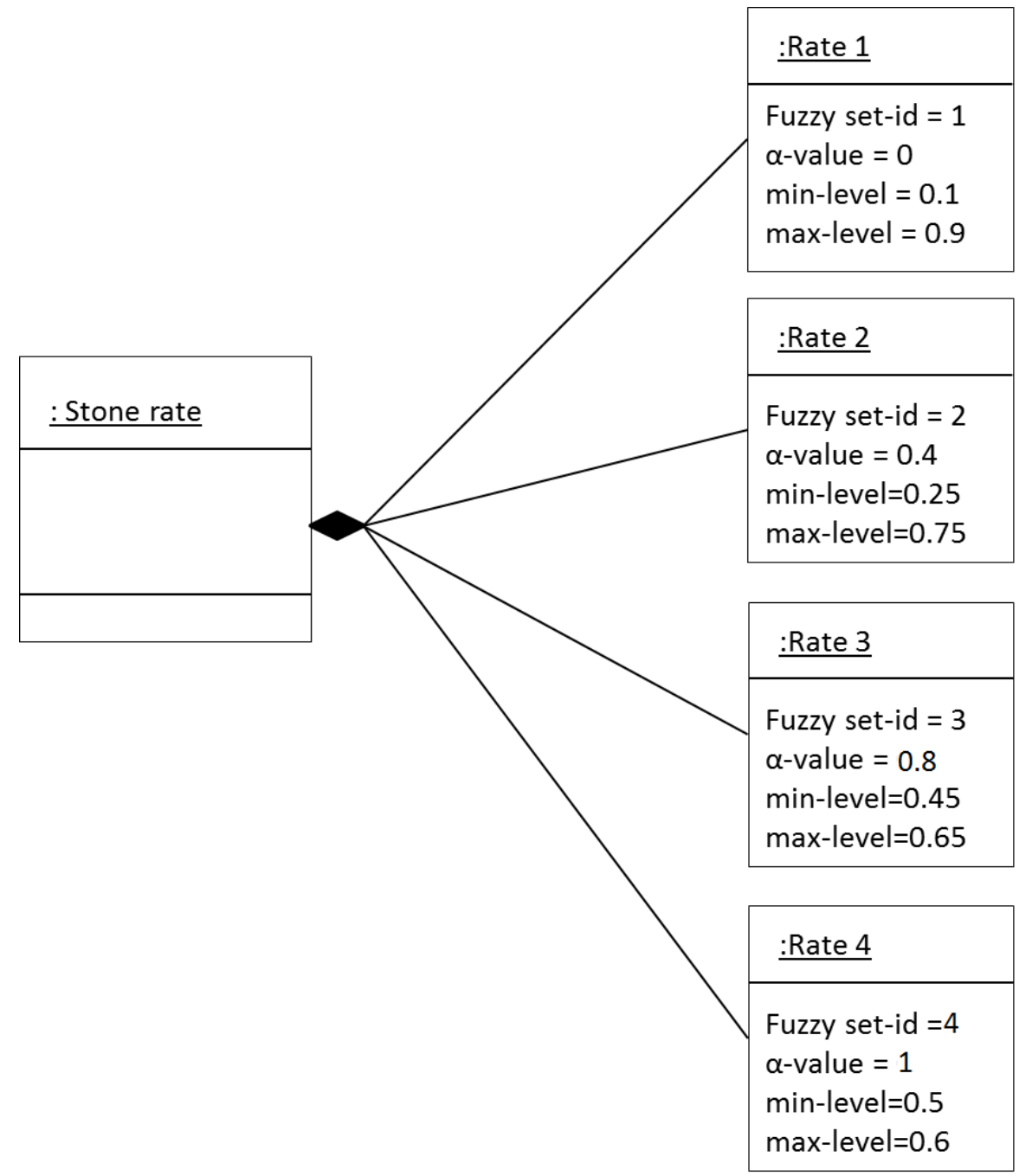

\subsubsection{Relational database view}

In a relational database, the fuzzy object class is transformed to the table 'Fuzzy_object'. This table is connected to the fuzzy object imprecision table which stores the fuzzy information as a multivalent set of values through the foreign key fuzzy set-id (Figure 8). 
Figure 8 A fuzzy object representation in a relational database view (see online version for colours)

Conceptual data model

Logical data model

Fuzzy_object_imprecision (fuzzy set-id, $\alpha$-value, min_level, max_level)

\begin{tabular}{|l|l|l|l|}
\hline fuzzy set-id & $\alpha$-value & min_level & max_level \\
\hline Id_1 & 0 & & \\
\hline Id_1 & 0.2 & & \\
\hline Id_1 & $\ldots$ & & \\
\hline Id_1 & 1 & & \\
\hline Id_2 & 0 & & \\
\hline Id_2 & 0.2 & & \\
\hline..- & & & \\
\hline
\end{tabular}

Fuzzy object

fuzzy set-id = fuzzy set-id

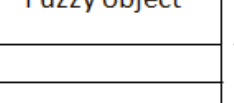

Fuzzy_object ( Fuzzy object-identifier, \#fuzzy set-id, ...)

In this article, as we have opted for the spatial relational database PostGIS, the integrity constraints are expressed in the procedural language PL/pgSQL.

Figure 9 Trigger for the verification of the fuzzy set structure of a fuzzy object

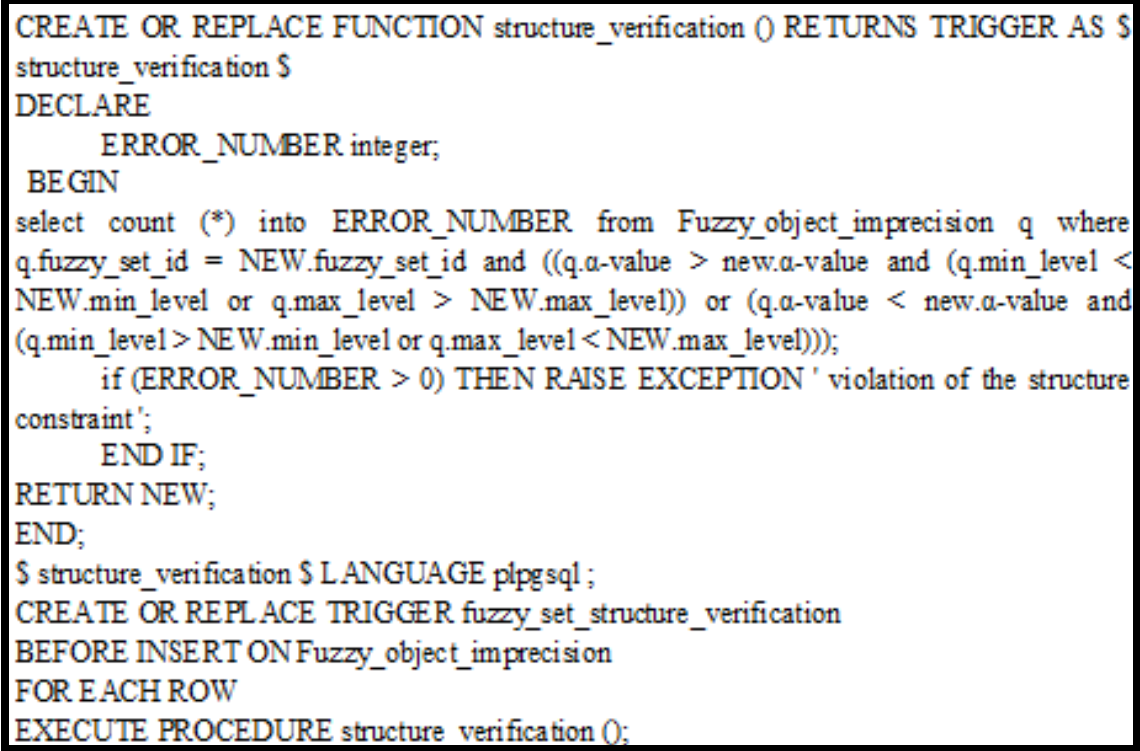


The constraint related to the connection verification of the fuzzy sets and which verifies the structure of the fuzzy sets in the table 'fuzzy_object_imprecision' is expressed in Figure 9.

\subsection{Modelling possibilistic data}

\subsubsection{Object database view}

The possibilistic object modelling is illustrated in Figure 10. According to this model, it is composed of at least one object of the class 'fuzzy object imprecision'. Thus, it has one or several possible hypotheses with different possibility degrees.

Figure 10 A possibilistic object representation in an object database view

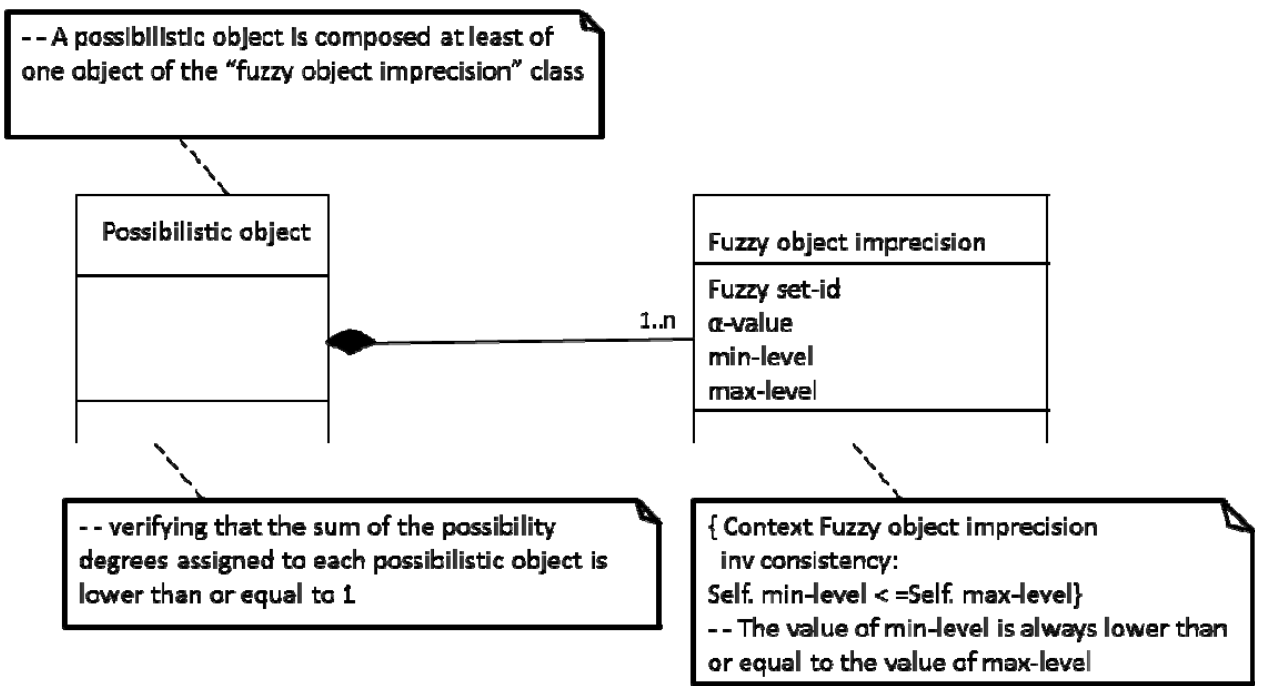

In this case, we check three constraints. The first constraint is to ensure that the value of the min-level is always less than, or equal to, the value of the max-level in the "fuzzy object imprecision' class. The second constraint consists of verifying that the sum of the possibility degrees assigned to each possibilistic object is lower than or equal to 1 . The third constraint is to ensure that a possibilistic object is composed of at least one object belonging to the 'fuzzy object imprecision' class.

\subsubsection{Relational database view}

The possibilistic object representation is a particular case of the fuzzy object representation. In fact, its possibility degrees correspond to one or several tuples of the table 'fuzzy_object_imprecision'. Thus, the possibilistic object class is transformed at the logical data model in the table 'possibilistic_object'. The latter is connected to the fuzzy object imprecision table through the foreign keys fuzzy set-id and $\alpha$-value (Figure 11). 
Figure 11 A possibilistic object representation in a relational database view (see online version for colours)

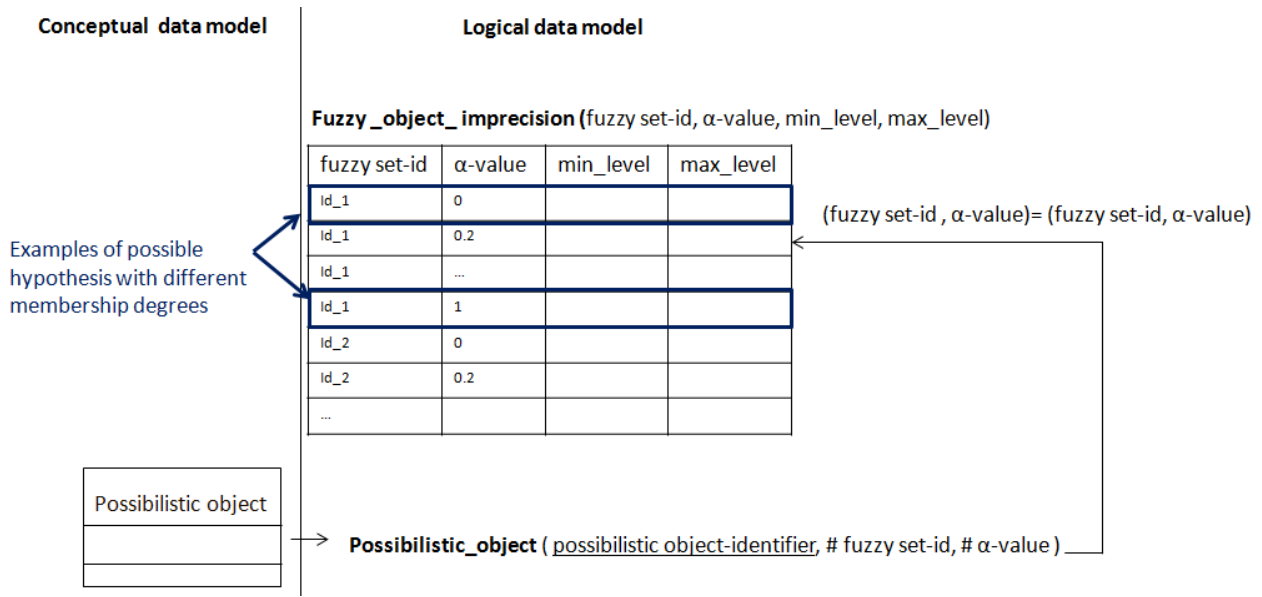

The constraint that checks the sum of the possibility degrees of each possibilistic object is expressed in PL/pgSQL in Figure 12.

Figure 12 Trigger for the verification of the sum of the possibility degrees

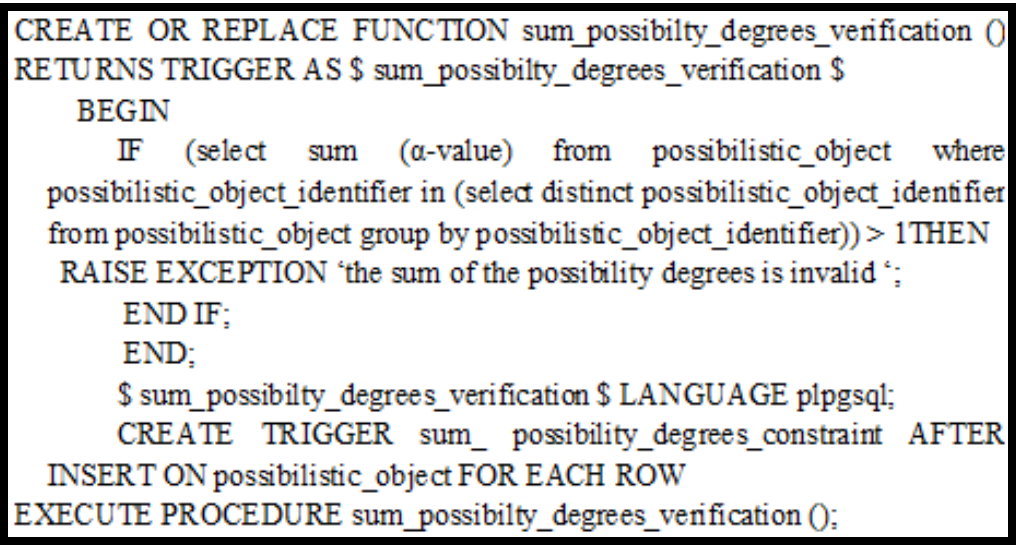

\section{Handling imprecise spatiotemporal information with F-perceptory}

\subsection{Conceptual modelling of spatiotemporal data}

The geographic information field proposed several methods for the design of spatiotemporal information systems. Some of these methods result from the adaptation of non-specific methods by the spatialisation and temporalisation of conceptual models like the perceptory model which is a spatiotemporal extension of the UML data model (Bedard, 1999). The other methods have their own tools for the design of geographic information systems. The most well known among them are MADS (Parent et al., 1997) and CONGOO (Pantazis, 1994). 
In this article, we are particularly interested in the perceptory method. This approach joins two main advantages. Firstly, it extends the standard object modelling language (UML) meta-model by spatial and temporal stereotypes. These allow an enriching of the UML data model by creating new spatial and temporal modelling elements and by assigning to them particular graphic representations called pictograms. As UML is usually exploited for designing information systems, extending UML is a critical point for our choice. MADS and CONGOO are not UML friendly. Secondly, perceptory is often used in GIS modelling because an extension to Visio was proposed and because its pictograms called PictograF can be used with other modelling tools such as modelio.

\subsubsection{Spatial data modelling}

The main pictograms used to model the spatial dimension of geographic entities are presented in Table 1. In this table, we have three simple geometries. The first one is a point geometry that represents the zero-dimensional objects. For instance, a building is represented by point geometry on a map if its size is smaller than $500 \mathrm{~m}^{2}$. The second one represents the one-dimensional objects. That is the case of a road which may have a linear geometry on a small scale. The third one is a polygon geometry that represents the two-dimensional objects. For example, a building is represented by polygon geometry on a map if its surface area is bigger than $500 \mathrm{~m}^{2}$.

Table 1 Main spatial pictograms in perceptory

\begin{tabular}{|c|c|c|}
\hline & Pictogaram & Description \\
\hline \multirow[t]{3}{*}{ Simple geometry } & $\bullet$ & Objects represented by a point (O D) \\
\hline & $/$ & Objects represented by a line (1 D) \\
\hline & 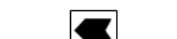 & Objects represented by a polygon (2 D) \\
\hline
\end{tabular}

\subsubsection{Temporal data modelling}

Temporal modelling relies on two fundamental concepts: the existence and the evolution. The existence of an object corresponds to its period of life which begins at its appearance date and ends at its disappearance date. The evolution characterises the various state changes of an object during its life. The pictograms used to model the temporal dimension of geographical entities are presented in Table 2.

Table 2 Temporal pictograms

\begin{tabular}{lc}
\hline Pictogram & Description \\
\hline $\mathbf{O}$ & One date recording \\
$\bigcirc$ & Two dates recording (time arrival) \\
\hline
\end{tabular}

The fuzzy extension introduced to UML is an inspiration source for the approach that we propose in order to model imprecise spatial and temporal data and that we detail in the next section. Indeed, fuzzy UML is used to model imprecise semantic and descriptive information in the class diagram through the introduction of new concepts like the fuzzy class and the fuzzy relations. However, despite its imprecision representation potential, fuzzy UML does not consider the temporality and the spatiality in its fuzzy model. 
Therefore, we propose to adapt the perceptory model to have a conceptual representation allowing the modelling of imprecise spatial, temporal and descriptive information (Figure 13).

Figure 13 Principle of F-perceptory (see online version for colours)

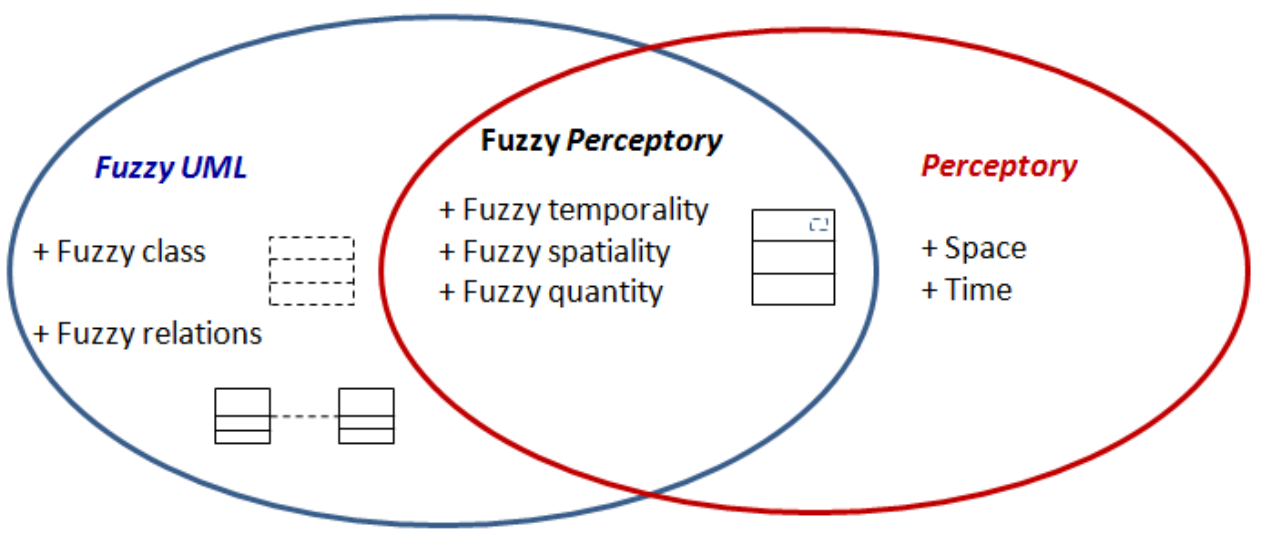

The conjunction of fuzzy UML and perceptory is the strength of our approach: F-perceptory. In fact, we adopt the fuzzy representation of classes and relations modelled by dashed lines in fuzzy UML, to enable the modelling of fuzzy temporality and spatiality in perceptory.

\subsection{Imprecise spatial data constraints}

We distinguish two types of spatial data imprecision. The first type is the fuzzy geometry that includes the forms fuzzy polygon, fuzzy line and fuzzy point. This type corresponds to spatial objects of which we cannot accurately determine boundaries. It is represented by enclosing the perceptory's spatial pictograms by a rectangular outline with dashed lines. The second type of spatial imprecision includes the valued geometries - which are geometries that are associated to a degree of possibility $\mathrm{d}$. Thus, we have the polygon shape associated to a degree of possibility d ('polygon with d'), the line shape associated to a degree of possibility d ('line with d') and the point shape associated to a degree of possibility d ('point with d'). The hierarchy of the spatial imprecision that we introduce into the perceptory data model is illustrated in Figure 14.

A set of spatial integrity constraints has to be checked in order to ensure the data consistency. We distinguish two types of spatial constraints: the constraints on fuzzy spatial data and the constraints on possibilistic spatial data.

We associate to each spatial imprecision type its equivalent representation in UML. In this representation, each spatial class will be connected to the class 'shape imprecision' that has a geometric type attribute (geom) and a degree of membership associated to it. The navigation from the spatial class to the class 'shape imprecision' is provided by the role 'geometries'. Inversely, the navigation from the class 'shape imprecision' to the spatial class is provided by the role 'spatial object'. 
Figure 14 Spatial imprecision in F-perceptory

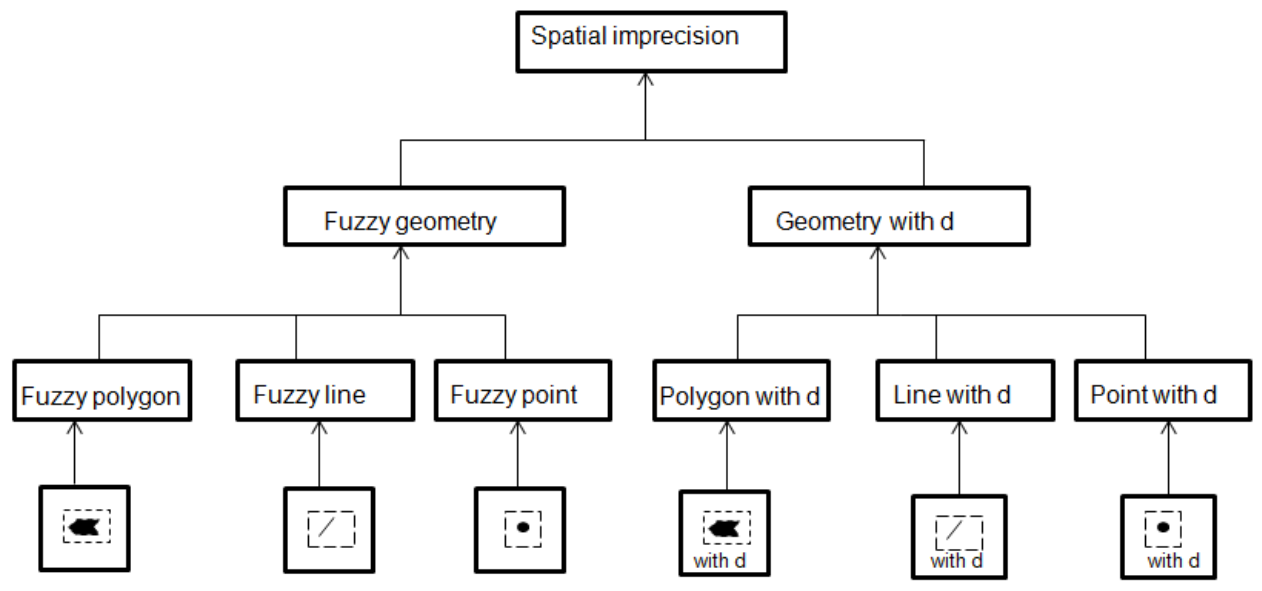

\subsubsection{Fuzzy geometries constraints}

The fuzzy geometry is related to geometric shapes of which we cannot accurately determine boundaries. Figure 15 presents a representation example of a fuzzy spatial object as the different interpretations that we can make on it through a set of connected $\alpha$-cuts.

Figure 15 Interpretation examples on connected $\alpha$-cuts for a fuzzy spatial object

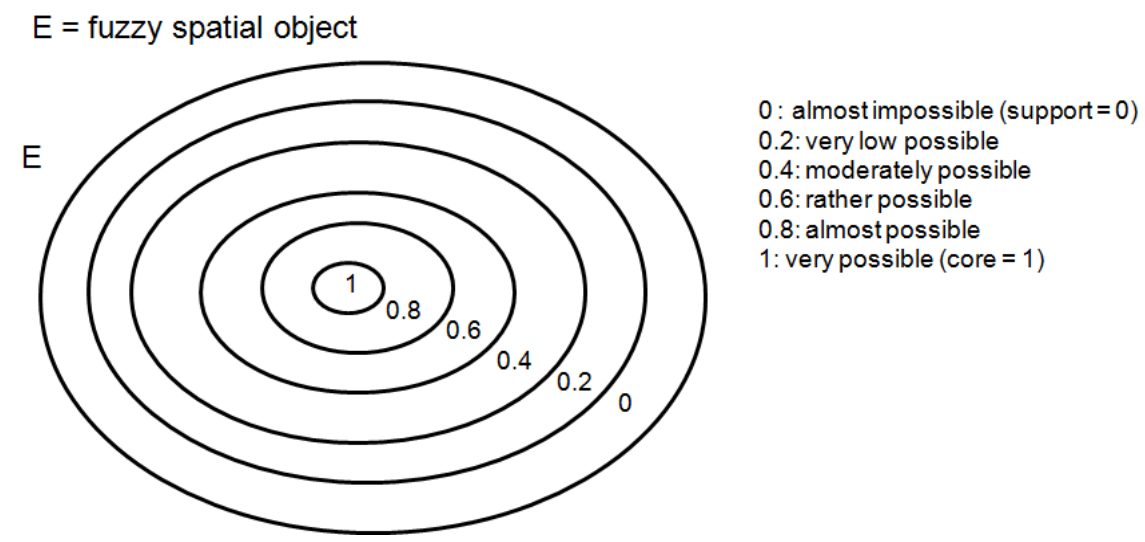

Figure 16 illustrates the UML representation of the fuzzy polygon. In the case of all the fuzzy geometries (fuzzy polygon, fuzzy line and fuzzy point), three main constraints have to be respected. The first constraint is to verify that the $\alpha$-cuts form a connected and normalised fuzzy set which means that:

- whatever the geometry G1 with a degree d1, all the geometries concerning our fuzzy set and having a degree higher than $\mathrm{d} 1$ are included in G1

- $\quad$ the geometric shapes are connected

- $\quad$ the maximum degree is equal to 1 . 
Figure 16 Example of constraints applied to fuzzy spatial data

UML

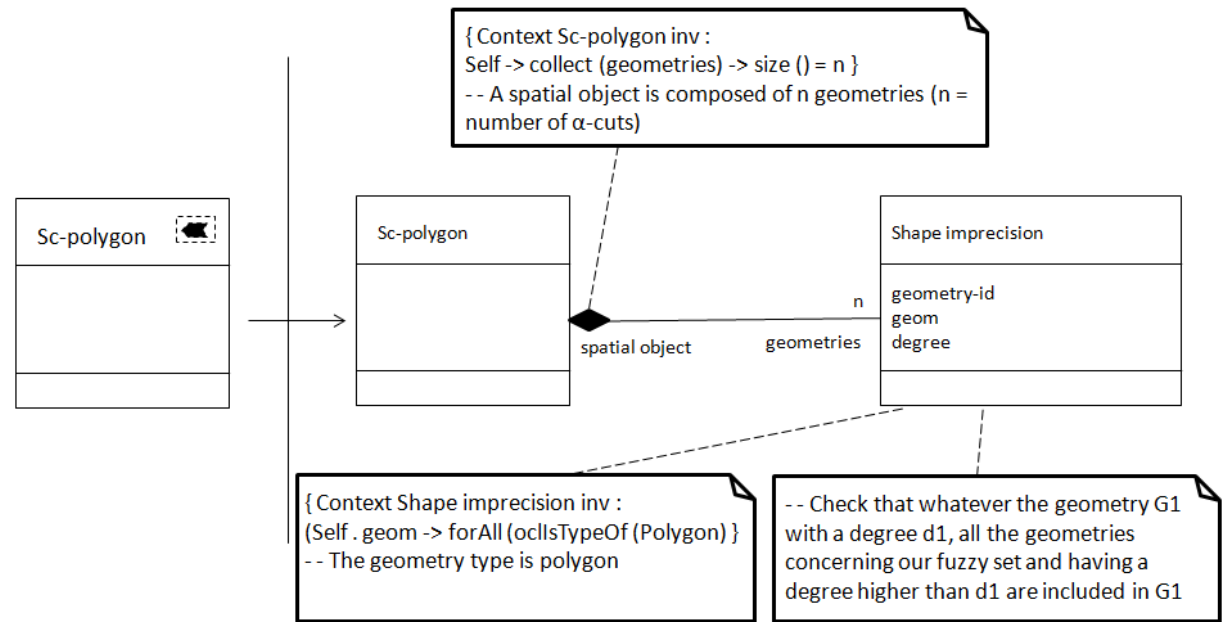

The second constraint ensures that each spatial object is composed of $\mathrm{n}$ geometries. The last constraint is to check that the attribute 'geom' has the type:

- polygon: in case of the fuzzy polygon

- $\quad$ line: in case of the fuzzy line and only if the degree is equal to 1

- $\quad$ point: in case of the fuzzy point and only if the degree is equal to 1 .

Figure 17 Trigger for the verification of the topological relation 'contains' on fuzzy polgon geometries

CREATE OR REPLACE FUNCTION contains_topological_relation_verification RETURNS TRIGGER AS S contains_topological_relation_verification S

DECLARE

ERROR_NUMBER integer;

BEGIN

select count $\left({ }^{*}\right)$ into ERROR_NUMBER from Shape_imprecision

where $t$ geometry id $=$ NEW. geometry id

and ((t.degree $>$ new.degree and not (St_contains (new.geom, t.geom) or (t.degree $<=$ new.degree and not (St_contains (t.geom, new.geom)); constraint';

if (ERROR_NUMBER > 0) THEN RAISE EXCEPTION ' violation of the structure

END IF;

RETURN NEW;

END;

S contains_topological_relation_verification S LANGUAGE plpgsql;

CREATE TRIGGER topological_relation_verification BEFORE INSERT ON Sc_polygon

FOR EACH ROW

EXECUTE PROCEDURE contains topological relation verification 0; 
Figure 17 illustrates an example of the connection constraint verification on the fuzzy polygon geometry.

Figure 18 A wooded area representation in an object diagram (see online version for colours)
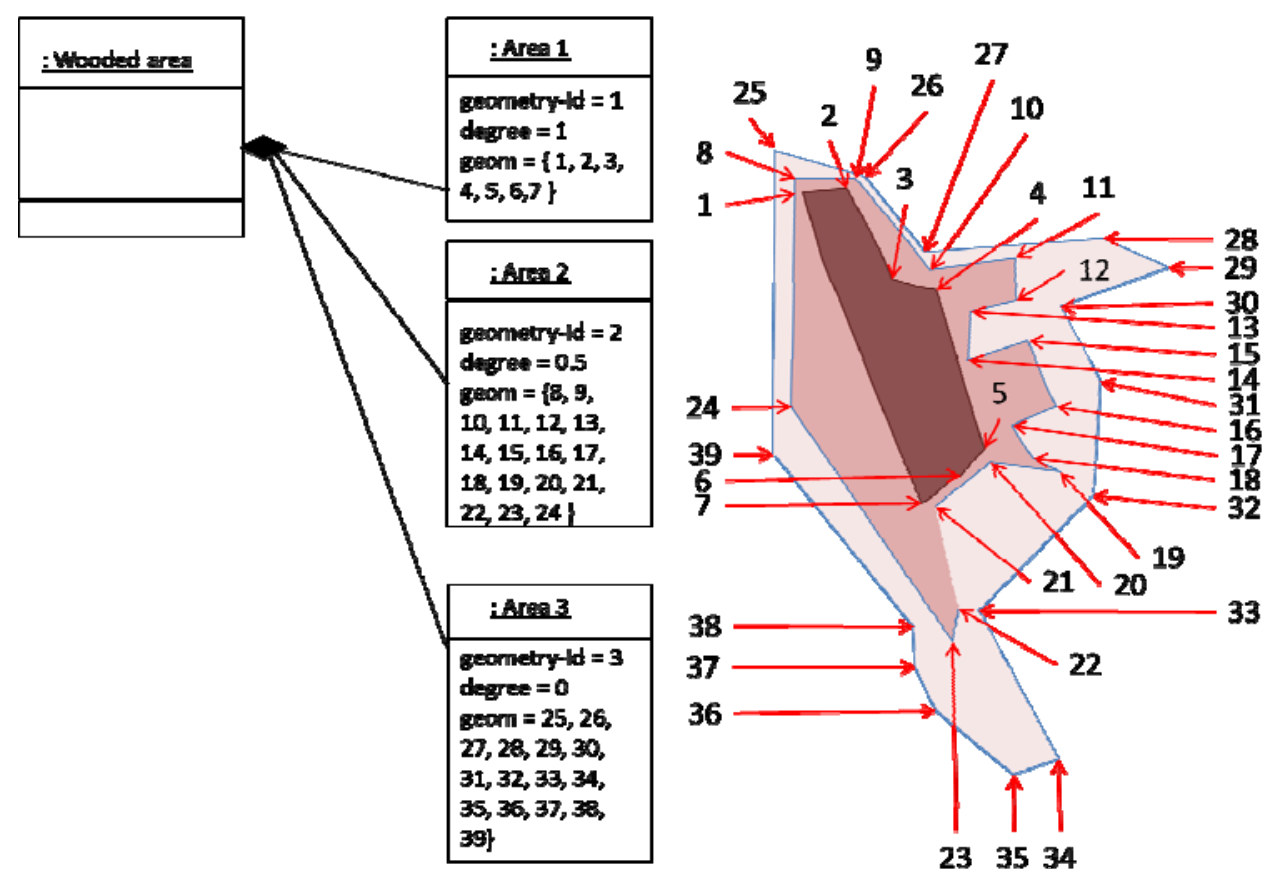

If we take the example of Figure 3, the wooded area will be composed of three areas as illustrated in the object diagram of Figure 18. In this representation, the geometry that determines each area is indicated in the form of numbers.

\subsubsection{Possibilistic geometries constraints}

In the case of the valued geometries, a spatial object is composed of one or many geometries with varying degrees of possibility. Thus, we need first to check that the sum of the possibility degrees of these different geometries is lower than or equal to 1 . Second, a spatial object has to be composed of at least one geometry and of at most $n$ geometries. Finally, the geometry defined in the 'shape imprecision' class has to be:

- a polygon: for the valued polygon

- a line: for the valued line

- a point: for the valued point.

The valued polygon constraints are represented in Figure 19. 
Figure 19 Example of constraints applied to possibilistic spatial data

UML

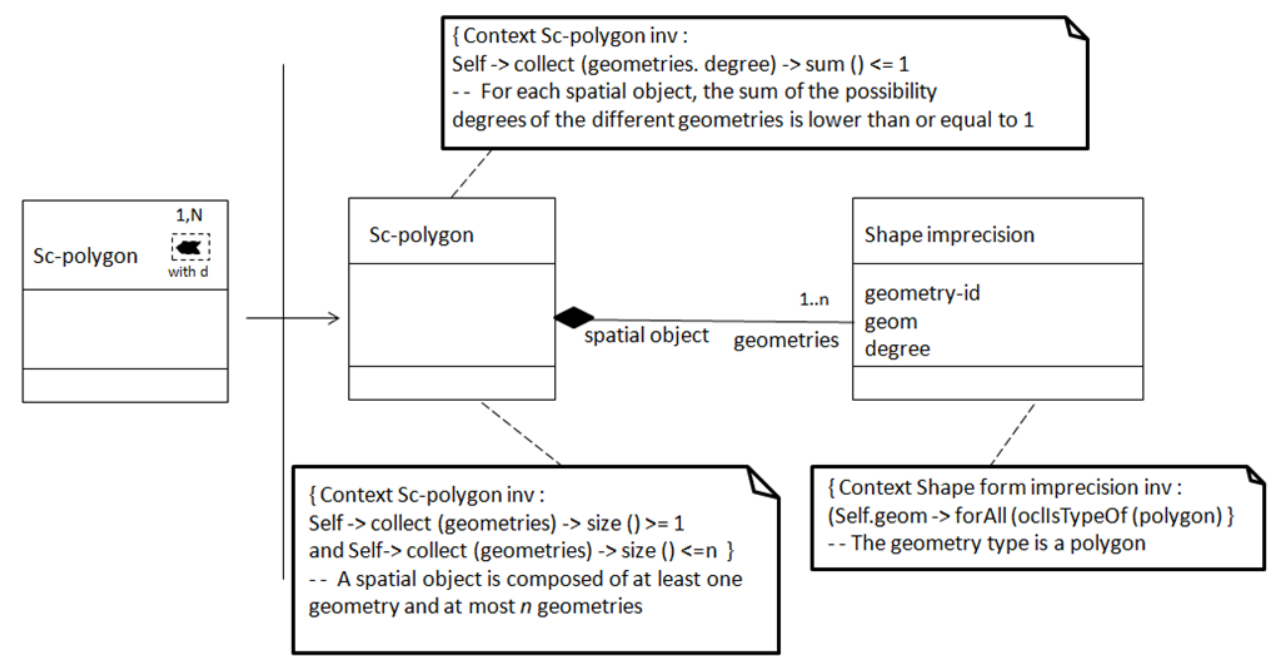

Figure 20 illustrates an example of a trigger expressed in the $\mathrm{Pl} / \mathrm{pgSQL}$ language that checks the sum of the possibility degrees assigned to each valued polygon $P_{i}$ of the table Sc-polygon, so that: $\sum_{k=1}^{n} \mu_{\text {geometry }}\left(P_{i}\right) \leq 1$.

Figure 20 Trigger for the verification of the sum of the possibilty degrees assigned to a valued polygon

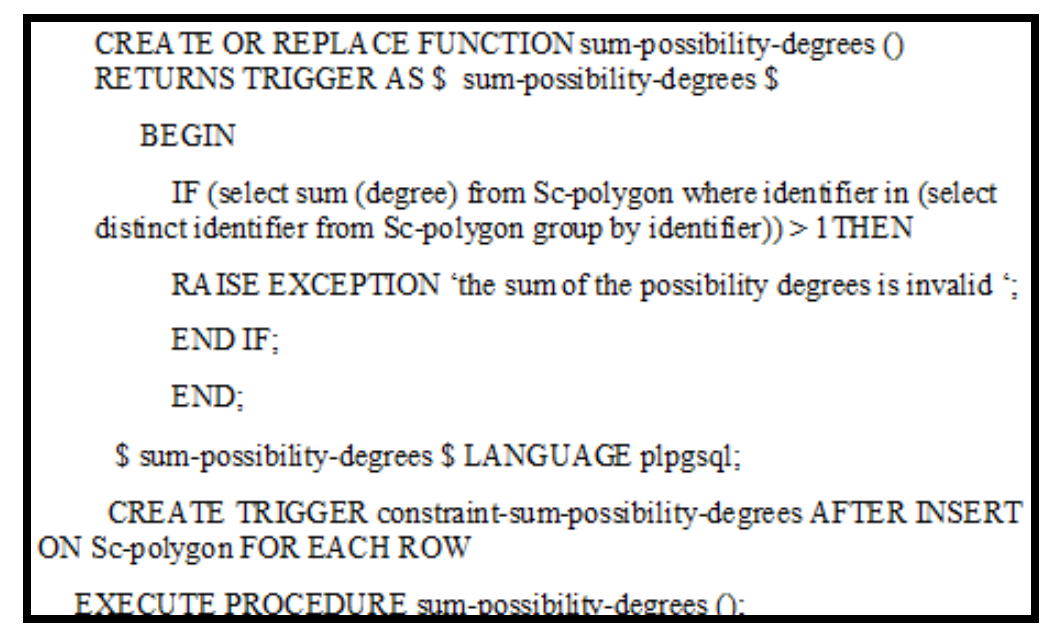

For instance, the distance between $\mathrm{A}$ and $\mathrm{B}$ shown in Figure 4 is composed of two possible values corresponding to the two data sources as illustrated in Figure 21. In this case, the geometry which determines each possible path between A and B is indicated in the form of numbers. 
Figure 21 A path representation in an object diagram (see online version for colours)

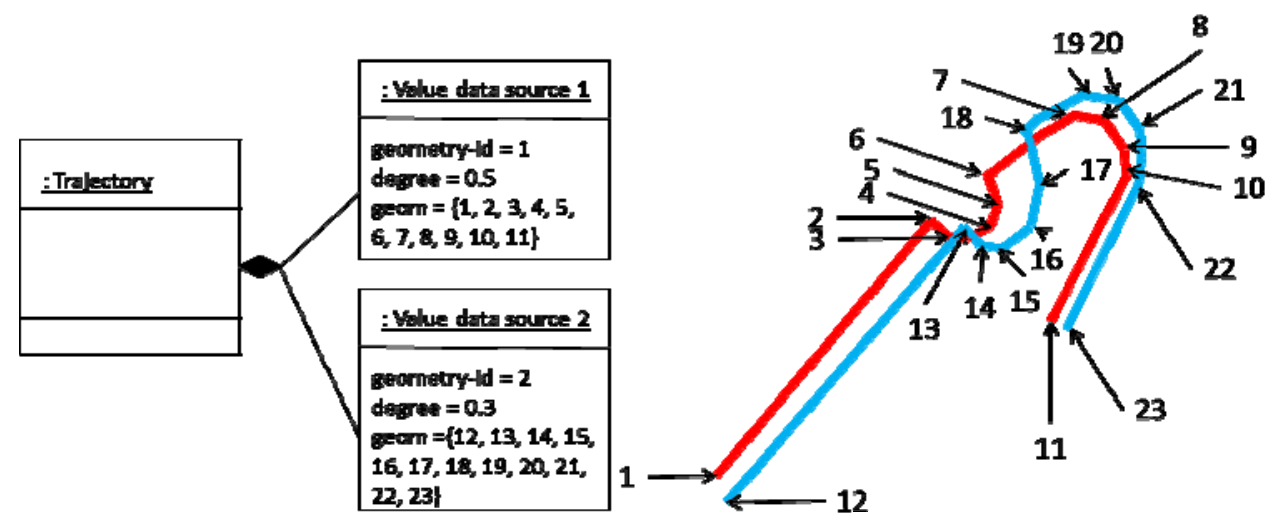

\subsection{Imprecise temporal data constraints}

As in the spatial imprecision, we distinguish two types of imprecision in the temporal case. The first type is a fuzzy timestamp that takes the form of a fuzzy period or a fuzzy date. This kind of imprecision is represented by enclosing the perceptory's classic time pictograms by a rectangular outline with dashed lines. The second type corresponds to a valued timestamp that associates to the temporality a value $d$ indicating a degree of possibility. Thus, we have the time period associated to a degree of possibility ("period with d') and the date associated to a degree of possibility ('date with d'). These temporal imprecision types that we introduce to the perceptory data model are illustrated in Figure 22.

Figure 22 Temporal imprecision in F-perceptory

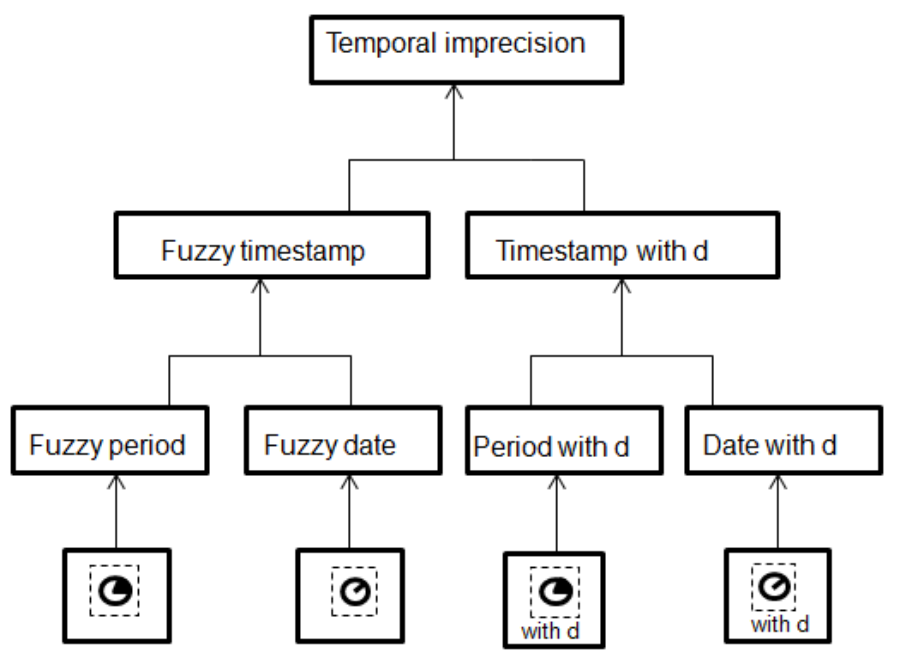


A set of temporal integrity constraints has to be checked in order to ensure the data consistency. We distinguish two types of temporal constraints: the constraints on fuzzy temporal data and the constraints on possibilistic temporal data.

We associate to each temporal imprecision type its equivalent representation in UML. In this representation, each temporal class will be connected to the class 'temporal imprecision'. The navigation from the latter to the temporal class is provided by the role 'date' or 'period' depending on whether the temporal class is respectively related to a fuzzy date or to a fuzzy period. Inversely, the navigation from the class 'temporal imprecision' to the temporal class is provided by the role 'temporal object'.

\subsubsection{Fuzzy temporal data constraints}

Figure 23 shows an example of constraints applied to fuzzy temporal data. There are three temporal constraints common to the fuzzy date and to the fuzzy period. The first one is related to the verification of the consistency of dates. Thus, the minimum date must be less than or equal to the maximum date in the 'temporal imprecision' class. The second constraint consists in ensuring that the fuzzy sets represented in the class 'temporal imprecision' and referring to dates or periods, are connected and normalised. The third constraint checks that a temporal object is composed of $n$ dates (in the fuzzy date case) and $n$ periods (in the fuzzy period case). In addition to these three constraints, we must check in the fuzzy date case that the values of the min-date and the max-date are equal if alpha is equal to 1 .

Figure 23 Example of constraints applied to fuzzy temporal data

UML

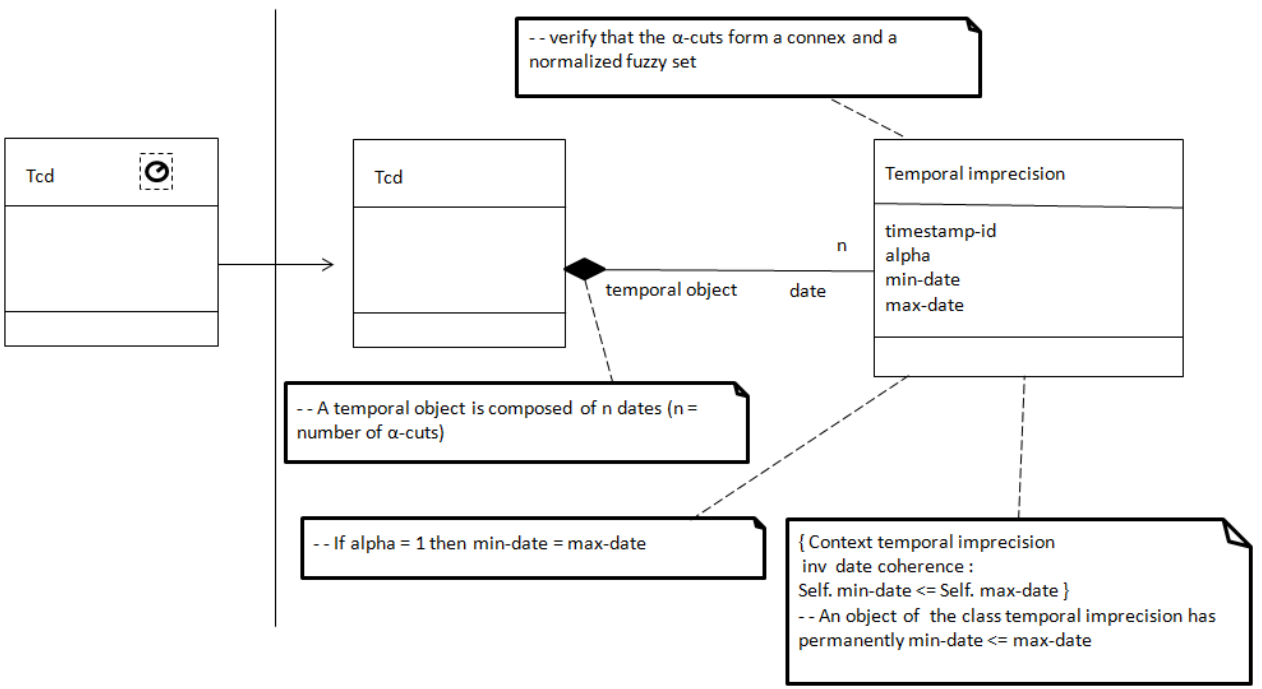

\subsubsection{Possibilistic temporal data constraints}

In addition to the classical constraint verifying the consistency of dates, the first constraint related to the valued dates and periods is to verify that, for a fuzzy date, a 
temporal object is composed of at least one date and of at most $n$ dates and that for a fuzzy period, it is composed of at least one period and of at most $n$ periods. In the second constraint, we check that the sum of the possibility degrees of the different dates and periods is lower than or equal to 1. These constraints are illustrated in Figure 24.

Figure 24 Example of constraints applied to possibilistic temporal data

UML

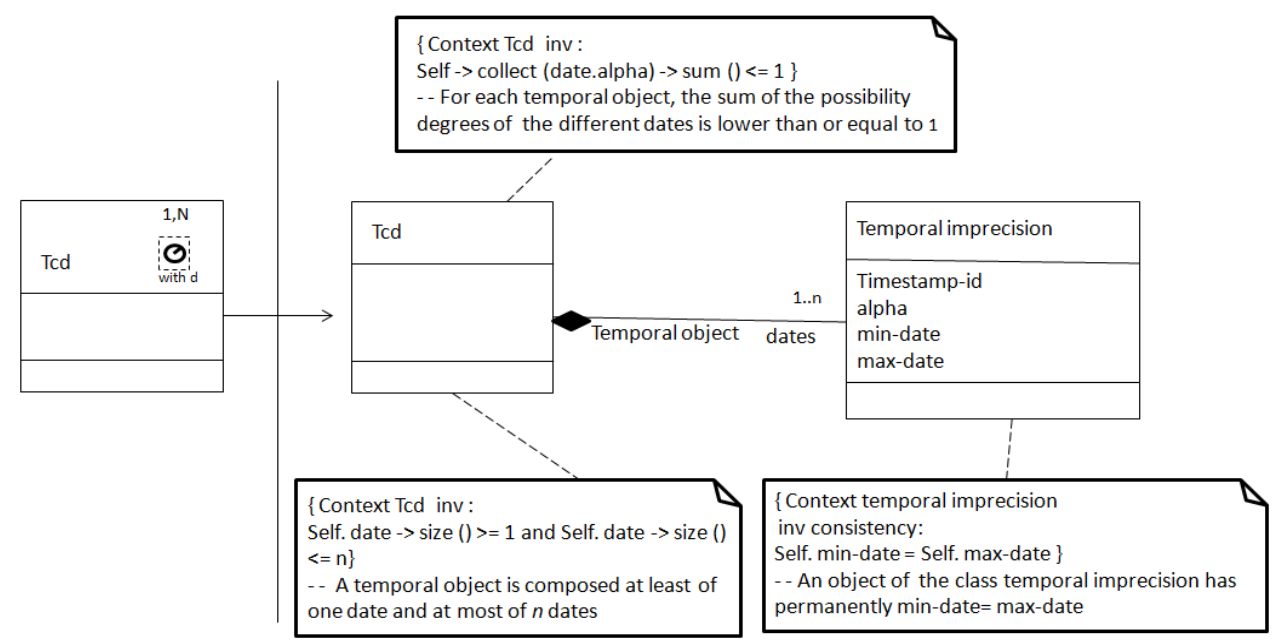

\section{Application on the construction of a spatiotemporal information system devoted to archaeological data}

By enquiring about the past, archaeological information is, by its essence, imperfect and its quality should be considered from the information system modelling to the analysis phase. Thus, data imperfection may be identified, characterised, memorised and queryable in an archaeological GIS. In the following section, we present an application that handles imprecise data in an archaeological information system.

\subsection{F-GISSAR: a fuzzy GIS for the representation and the analysis of archaeological data}

Since the beginning of the 1980s, the need of excavation data storage has appeared and some information systems devoted to archaeological data were deployed. The first archaeological database in Reims (France) called GISSAR (Piantoni and Pargny, 2005; Desjardin and Pargny, 2009) was built in 1983. The first objective of GISSAR was to gather data belonging to an older database and collected during the different excavations of archaeological sites. Then, it aimed to provide archaeologists with a tool enabling the entry of new sites. 


\subsubsection{The GISSAR archaeological data model}

Handling urban archaeological data is the main issue in order to understand the past and to restore knowledge to citizens. In Europe and particularly in Reims (France), there were many invasions and wars and, therefore, much destruction/construction. Thus, the storage and visualisation of archaeological data are essential.

In urban excavations, there are two principal studied spatial objects. On one hand, the studied site is of prime importance because it locates the phenomenon and it may give information about the global past print. On the other hand, there are the archaeological entities that are present in an excavation site.

Those entities correspond to the excavated objects that represent marks about the past structure such as a wall, a room or a building.

An urban archaeological entity is structured over seven spatial scales from the stratigraphic unit to the interurban area. On a more global scale, an entity may be composed by some objects representing data at a more local scale. Therefore, the information system may allow the storage of archaeological sites which contain archaeological entities. An archaeological entity may aggregate other archaeological entities. The scales of objects are obtained by specialising archaeological entities.

GISSAR is a spatiotemporal database devoted to storing archaeological data related to the city of Reims. We developed the GISSAR data model using the PictograF language of perceptory.

Urban excavation data in this database are considered according to the triplet timespace-description as detailed in Rodier and Saligny (2007). In this triplet, there are generally seven spatial scales from the stratigraphic units to the urban areas.

According to the conceptual model presented in Figure 25, we define the geometry chosen for each spatial class. For example, the archaeological entities are considered as areas while the geometric type representation of artefacts and documentations is a point.

To represent the dating corresponding to possible periods or centuries, temporal entities which have a sustainable existence, like the archaeological entities or the artefacts are represented by a pictogram indicating a time interval whereas the documentation class which has an instantaneous existence is represented by a pictogram indicating its creation date.

Time is an integrate component of excavation objects and it is generally represented by a period of time. In addition to their spatial and temporal characteristics, the archaeological entities and the artefacts have descriptive characteristics such as the dimension (height, width, thickness, length, etc.). The archaeological entity is linked to the material class that provides a description of all the materials of which it is composed. The artefacts also have their own description in terms of materials. Figure 24 presents an extract of the GISSAR class diagram describing the structure of the excavation GIS. The whole class diagram of GISSAR is detailed in Zoghlami et al. (2012b).

A previous version of this system is currently used for storing excavation data in Reims but it does not allow for the taking into consideration the data imprecision. 
Figure 25 An extract of the GISSAR class diagram

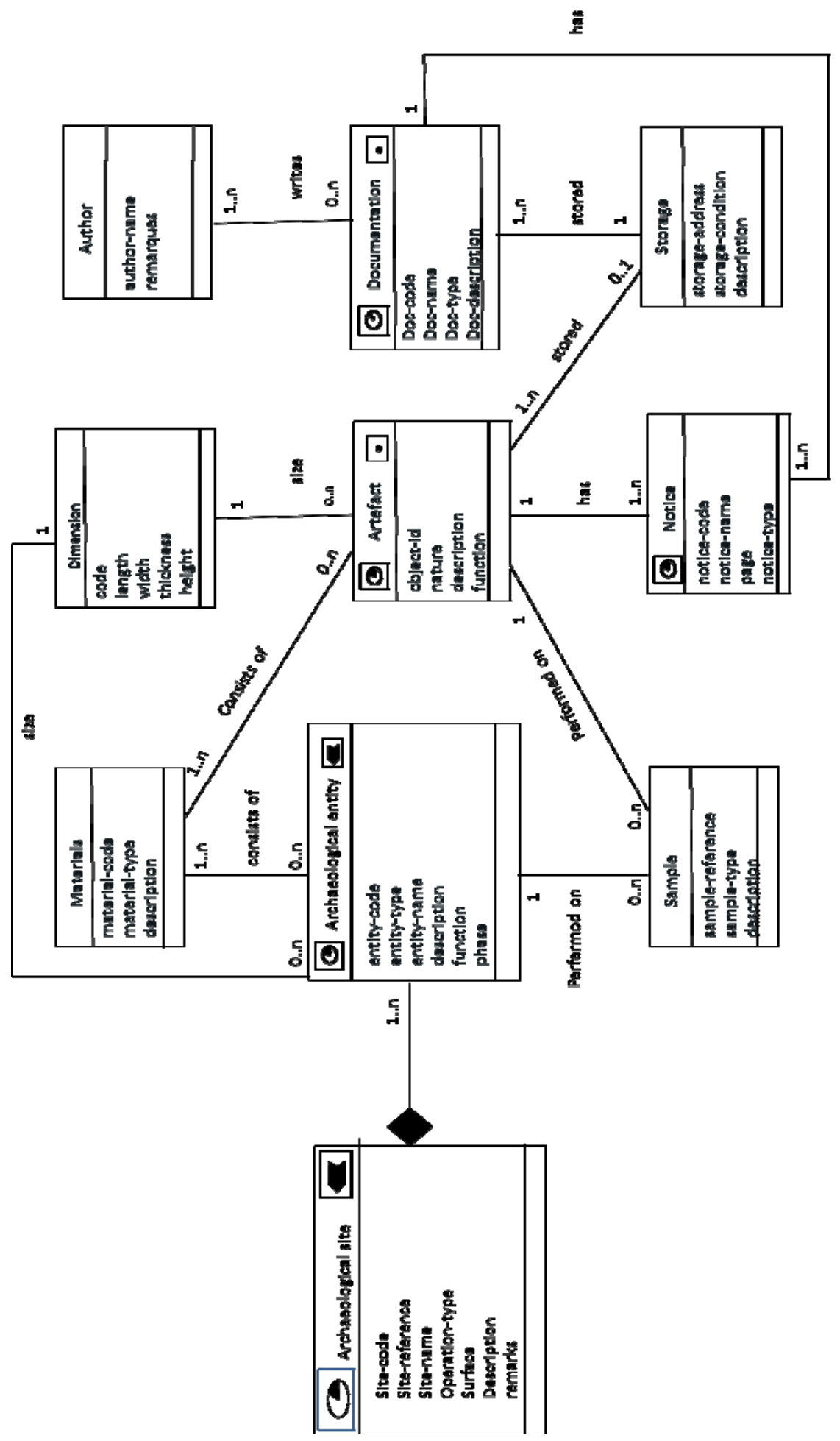




\subsubsection{Identification of imprecise information in GISSAR}

We find the imperfection in all of the process handling archaeological data - starting from the data acquisition, continuing with data representation and management and ending by data visualisation. This is due to the particularity of the archaeological data which is an instance of a triple relation between time, space and function.

Indeed, the time interval between the excavation and the activity period of an object implies some imprecision/uncertainty: partial destruction, soil movement, estimation of activity period, estimation of descriptive attributes, etc.

Quantitative information is often defined using qualifiers. For instance, the type of stone shape in a wall tends to use qualifiers as long, thick, thin and large or even moderately thick, very thin and a little bit large. It is meaningful in the case of artefact storage.

The semantic imperfection concerns the archaeological instance composition. For example, sometimes one wonders whether an instance contains iron or whether it is a marble or not. It also concerns the archaeological instance function which can sometimes be uncertain.

The temporal information is related to the activity period of the object. We often have imprecise information concerning the existence of an historical event or an object because its description takes the form of sentences like 'it happened at the beginning of the second century', 'it was at the middle of a period', or 'it happened during the third century'. Sometimes it also takes the form of expressions such as 'it was at the very beginning of a century', or 'it was right in the middle of a period' and so one.

Spatial data includes information regarding the geometry and the location of an instance on Earth. In classic approaches, spatial archaeological instances are usually represented as objects with well-defined boundaries (points, lines, regions) even if they are vague by nature like the boundaries of a stratigraphic unit or an archaeological site. The location of an instance can be made by using reference points, benchmarks, the expert positioning and through old repositioned maps. Thus, georeferencing an instance is usually related to a lack of precision.

In the GISSAR data model, we distinguish different levels of imprecision. The first level concerns the imprecision on the descriptive characteristics (dimension, composition, etc.). In fact, we describe the dimension by fuzzy predicates such as thick, high, long, etc.

The second level of imprecision is related to time. Temporal features of archaeological entities correspond to time periods where the considered objects were active. This dating presents a lack of precision, since we cannot precisely identify the two terminals of the time interval.

The last level is related to space, namely the geometry shape of spatial objects that may have fuzzy boundaries and also the imprecision of their georeferencing. 
Figure 26 Extract from the F-GISSAR model (see online version for colours)
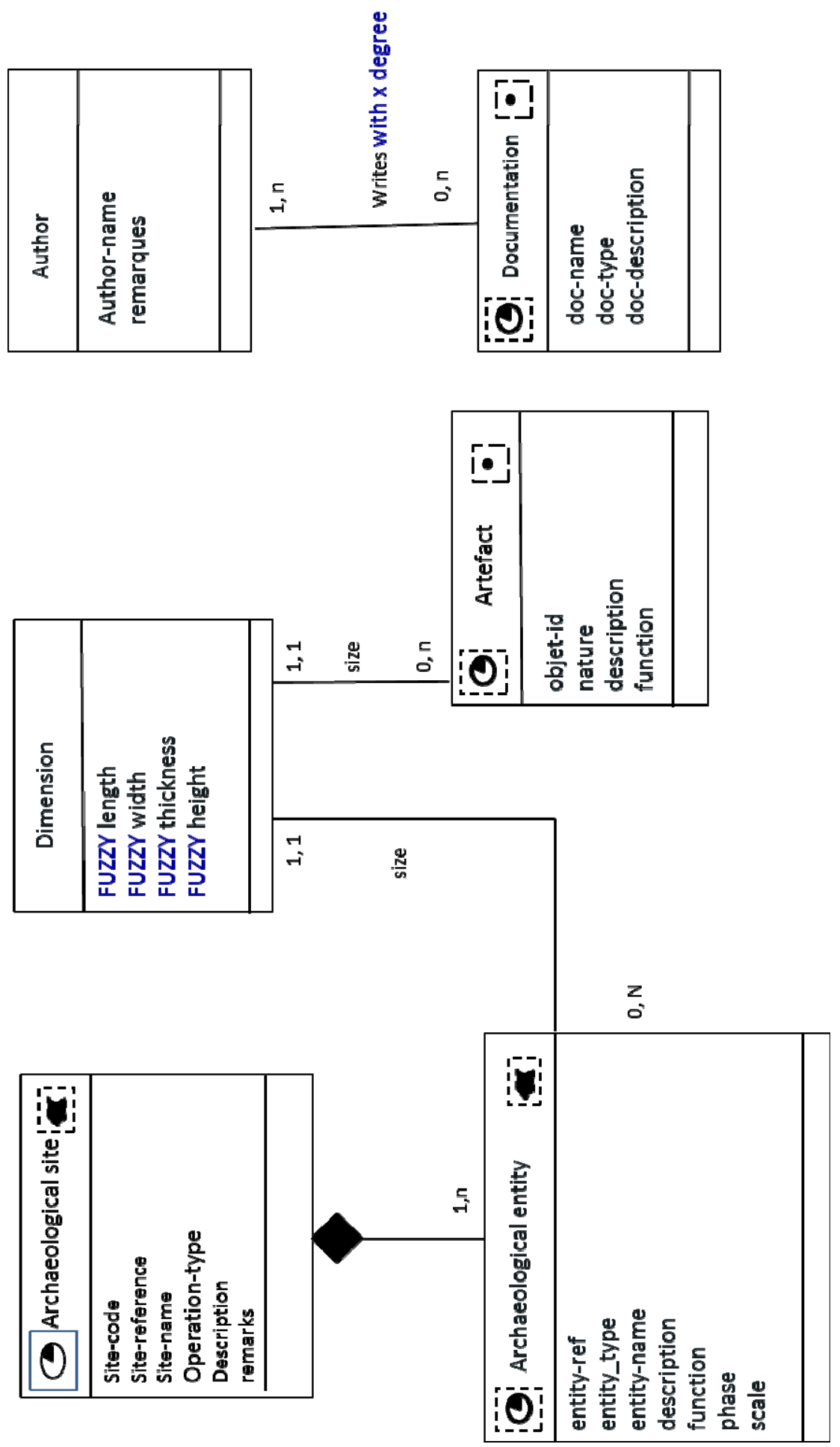


\subsubsection{F-GISSAR data model}

To handle the first level of imprecision the keyword FUZZY is introduced and placed in the dimension class in front of the fuzzy attributes such as length, width, height and thickness. Imprecise spatial and temporal information are modelled using the F-perceptory pictograms. The temporal imprecision is modelled through the fuzzy period while the fuzzy boundaries of archaeological entities and sites are considered as fuzzy polygons. The artefacts and documentations are considered as fuzzy points. Figure 26 presents an extract from the F-GISSAR data model highlighting the three levels of imprecision in the GISSAR model.

\subsubsection{F-GISSAR database structure}

As the main goal is to store fuzzy spatiotemporal data, we choose to build a system that organises the information into two layers. A first layer containing the geometric data is implemented. This layer is called the data layer; it contains the geometric data like shapes and locations of the archaeological instances, the descriptive data referring to all the object descriptive attributes and the temporal data related to all the temporal classes that we have previously mentioned. A second layer (multi-valued layer) associated to the data layer is implemented. It handles the various quantitative, spatial and temporal forms of imprecision.

To handle the quantitative qualifier imprecision which is due to the use of natural language terms, all the fuzzy attributes are connected to a special table that stores the imprecise information as a multivalent set of values through an intermediate table that references their fuzzy set identifier.

For the spatial data, we create a spatial imprecision table which includes all the fuzzy geometric shapes corresponding to archaeological sites, archaeological entities, artefacts and documentations. All the spatial queries will refer to this table.

For the temporal data, all the temporal entities are connected to a temporal imprecision table that stores all the semantic expressions referring to the date as a multi-valued set of values. The connection with this table is possible through an intermediate table that includes the fuzzy set identifier for each dating reference.

Using the previous database tables, we are now able to build operational GIS devoted to archaeological information.

\subsection{Operating example of F-GISSAR: querying imprecise spatiotemporal data}

We consider the request aiming to find the entities that satisfy the following conditions:

- $\quad$ their activity period is the 2 nd century (with at least a degree of 0.4 )

- their shape belongs to the site 'PC 87'

- $\quad$ the final degree must be at least equal to 0.8 .

This request corresponds to an $\alpha$-cut with $\alpha$ equal to 0.8 and could be expressed as follows:

$$
(\operatorname{ActivityPeriod}(x) \sim 2 \text { nd Century AND Shape }(x) \sim \operatorname{PC} 87)>=.8 .
$$

Using the Zadeh t-norm, this implies that: 
$\operatorname{Min}(\operatorname{AvtivityPeriod}(x) \sim 2$ nd Century, Shape $(x) \sim \operatorname{PC} 87)>=0.8$.

The:

$\operatorname{ActivityPeriod}(x) \sim 2$ nd Century $>=0.8$ AND Shape $(x) \sim \operatorname{PC~} 87>=0.8$.

Figure 27 Database extraction of entities with temporal imperfection

\begin{tabular}{|l|l|l|l|l|}
\hline & $\begin{array}{l}\text { entity_id } \\
\text { integer }\end{array}$ & $\begin{array}{l}\text { entity_reference } \\
\text { character varying }\end{array}$ & $\begin{array}{l}\text { date_reference } \\
\text { character varying }\end{array}$ & $\begin{array}{l}\text { degree } \\
\text { numeric }\end{array}$ \\
\hline $\mathbf{1}$ & 360 & G1 52 & mid 2nd centurv & 0.8 \\
\hline $\mathbf{2}$ & 355 & Mr 47 & mid 2nd centurv & 0.4 \\
\hline $\mathbf{3}$ & 356 & Mr 48 & mid 2nd centurv & 0.8 \\
\hline $\mathbf{4}$ & 354 & Fs 46 & mid 2nd centurv & 0.6 \\
\hline $\mathbf{5}$ & 358 & Fs 50 & mid 2nd centurv & 1 \\
\hline $\mathbf{6}$ & 353 & Mr 45 & mid 2nd centurv & 0.4 \\
\hline $\mathbf{7}$ & 357 & Mr 49 & mid 2nd centurv & 0.8 \\
\hline
\end{tabular}

Figure 28 Query with spatial imprecision

\begin{tabular}{|l|l|l|l|l|}
\hline & $\begin{array}{l}\text { entity_id } \\
\text { integer }\end{array}$ & $\begin{array}{l}\text { shape_id } \\
\text { integer }\end{array}$ & $\begin{array}{l}\text { geometry } \\
\text { geometry }\end{array}$ & $\begin{array}{l}\text { degree } \\
\text { numeric }\end{array}$ \\
\hline $\mathbf{1}$ & 1 & 233 & $0103000020 \mathrm{E} 610000$ & 1 \\
\hline $\mathbf{2}$ & 2 & 233 & $0103000020 \mathrm{E} 610000$ & 0.8 \\
\hline $\mathbf{3}$ & 351 & 233 & $0103000020 \mathrm{E} 610000$ & 1 \\
\hline $\mathbf{4}$ & 356 & 233 & $0103000020 \mathrm{E} 610000$ & 0.8 \\
\hline
\end{tabular}

Figure 27 illustrates an example of the query returning the entities having an activity period in the 2 nd century. Figure 28 shows the result of the query returning the entities that belong to the site PC 87 . According to this example the entity having the identifier 356 is the only one that satisfies the two conditions.

The visualisation of the query combining the spatial and the temporal imperfection is illustrated in Figure 29.

Figure 29 Visualisation of entities that have an activity 'middle of the 2nd century' and belong to site PC 87 (see online version for colours)

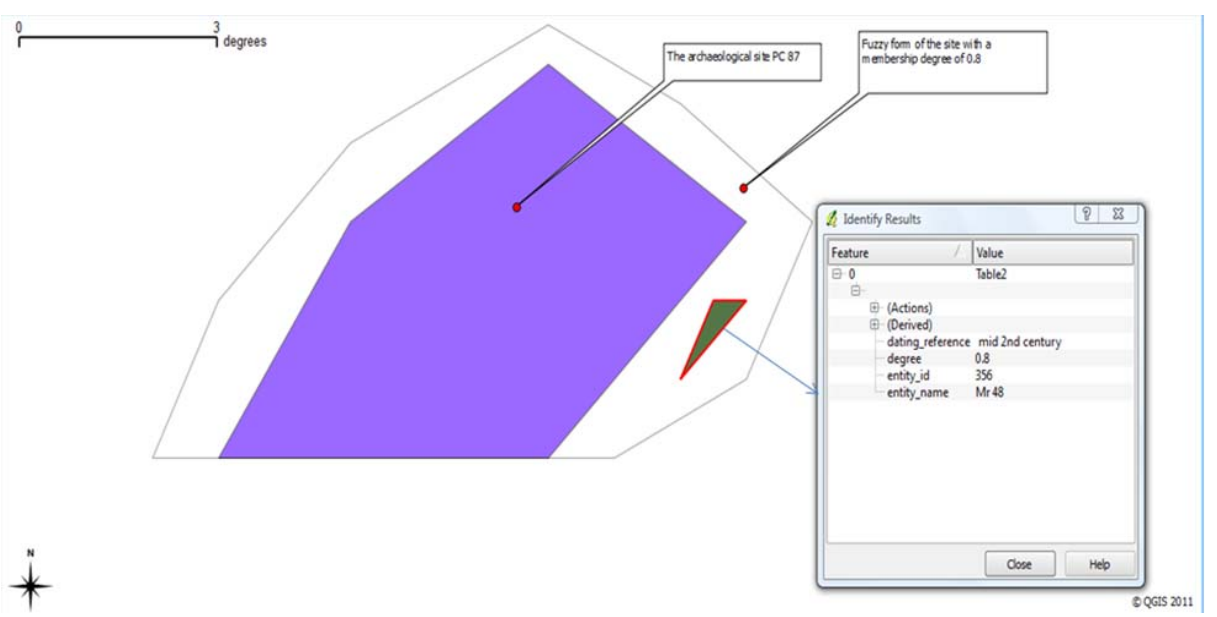




\section{Discussion}

\subsection{About modelling imprecise spatial information}

Since Burrough and Frank (1996), the literature supplies many approaches dealing with imprecise spatial data modelling (Clementini, 2005; Erwig and Schneider, 1997). They are defined according to mathematical theories of uncertainty: conjunction of crisp sets, rough set theory, fuzzy set theory, etc.

The models based on crisp sets take several crisp sets in order to represent a region according to different hypotheses. The 'egg-yolk model' (Cohn and Gotts, 1996) introduces the concept of regions with broad boundaries for representing an indeterminate boundary. A spatial object with broad boundaries is composed of two crisp regions: the 'yolk' region represents the certain part (the minimal extension) of the spatial object; the 'egg' is the crisp region that represents the possible part (the maximal extension). Clementini and di Felice $(1996,1997,2001)$ propose another view of the 'egg-yolk' model based on the point-set topology. The 'qualitative min-max' model (Bejaoui et al., 2009) allows the representation of a partially vague region.

The rough set theory was introduced in Pawlak (1982). A rough set is a formal approximation of a crisp set in terms of a pair of crisp sets which give the lower and the upper approximation. This theory is well adapted to the issues in databases in which we cannot evaluate the membership of a data to a class: if a data respects a minimum of the studied class properties, it will be affected to the lower approximation and if it respects all the class properties, it will be considered as a member of the upper approximation. Rough sets are structured on the notion of the possibility and the necessity of the membership of an element to a set.

Worboys (1998) uses this theory for modelling a vague spatial object. The difference between the lower and the upper approximation defines the vague boundary of an object. If this difference is null, the region is then crisp.

Those models using multiple crisp sets or rough sets allow us to easily conceptualise imprecise regions but do not provide a quantitative assessment of the membership of an element to a set. This need of graduation was highlighted with the sorites paradox.

In order to deal with this, the use of the fuzzy set theory is a classic and it is the main reason we exploit it in our approach. Nevertheless, the storage of continuous membership functions is complex and expensive. As a solution, some approaches exploit a valued discretisation of fuzzy sets.

Our approach for the storage is directly inspired by Morris and Petry (2006). They model fuzzy objects as a collection of ' $\alpha$-cut level regions'. Each ' $\alpha$-cut region' is therefore a crisp region with a membership degree $\alpha$. As our approach is based, for fuzzy spatial objects, on their storage as multiple valued sets according to $\alpha$-cut, a wrapper between the F-perceptory database and UGML may easily be built.

In Schneider (1999), the author proposes a fuzzy region model for fuzzy spatial data types. Using this model, the notion of fuzzy point, fuzzy line and fuzzy region may be defined in $\mathrm{R}^{2}$. A similar modelling has been proposed in Tøssebro and Nygård (2002) and in Worboys and Clementini (2001). This process facilitates the exploitation of fuzzy objects in a GIS and maintains the interest of the valued confidence contribution. This is, combined to the perceptory principle, one of the main reasons we have mainly defined for spatial data the three pictograms for fuzzy polygons, fuzzy lines and fuzzy points. 
Finally, as our approach is based on the modelling of fuzzy data through multiple $\alpha$-cuts, it could also be compatible with the Worboys and egg-yolk models by reducing the number of the stored $\alpha$-cuts to $2(\alpha=0$ and $\alpha=1)$. Thus, F-perceptory may be viewed as a possible approach for dealing with many forms of imprecise data modelling.

\subsection{About fuzzy extension for modelling databases}

In the literature, several studies have focused on introducing fuzzy extensions on relational database models and on object-oriented database models in order to store imprecision. We can classify these studies into two different groups.

The first group includes works that are interested in establishing fuzzy queries taking into consideration the imprecision in the database. In this case, we mainly mention the work of Bosc and Pivert (1995, 2000).

The second group includes works that are interested in proposing new data models to store imprecise information in traditional relational and object-oriented databases. We can mainly mention the recent works of Gupta et al. (2011) and Škrbić et al. (2011).

In Table 3, we propose a comparative study between our model and the main fuzzy conceptual database models. The first model is the fuzzy ER model in which Zvieli and Chen (1986), Vandenberghe (1991), Ruspini (1986) and Vert et al. (2002) have proposed an extension of the ER model to represent fuzzy entities, fuzzy relations, etc. The second model is the fuzzy EER model which extends the EER models in order to represent fuzzy attributes, fuzzy classes, etc. as presented in Galindo et al. (2004), Chen and Kerre (1998) and Ma et al. (2001). The third model is the fuzzy UML data model. According to this table, the fuzzy ER model is adapted to applications in fuzzy relational database models. The fuzzy EER model and the fuzzy UML model are applied to model fuzzy object-oriented databases. However, even though the modelling of imprecise spatiotemporal objects can be done through classic modelling (Schneider, 1996) or through meta-modelling (Frank, 1998), these fuzzy data models are not adequate to represent and store fuzzy spatiotemporal data. By contrast, our model is adapted to handle imprecise spatiotemporal data in both relational databases and object-oriented databases.

Table 3 Design of fuzzy databases through fuzzy conceptual models: a comparative study

\begin{tabular}{lcccccc}
\hline & \multicolumn{2}{c}{ Application in fuzzy database models } & & \multicolumn{2}{c}{ Fuzzy spatiotemporal databases } \\
\cline { 2 - 3 } & $\begin{array}{c}\text { Fuzzy relational } \\
\text { database }\end{array}$ & $\begin{array}{c}\text { Fuzzy object } \\
\text { oriented database }\end{array}$ & & $\begin{array}{c}\text { Fuzzy } \\
\text { relational } \\
\text { database }\end{array}$ & $\begin{array}{c}\text { Fuzzy object } \\
\text { oriented } \\
\text { database }\end{array}$ \\
\hline Fuzzy ER model & Yes & No & & No & No \\
Fuzzy EER model & No & Yes & & No & No \\
Fuzzy UML model & No & Yes & & No & No \\
F-perceptory & Yes & Yes & & Yes & Yes \\
\hline
\end{tabular}

We propose, in Table 4, a comparison between the main spatiotemporal modelling methods (MADS and perceptory) and our approach F-perceptory.

The fuzzy and uncertain extension of the MADS method introduced by Shu et al. (2003) has clearly defined the spatial/temporal randomness and the spatial/temporal fuzziness. The first one is manifested in geographical or temporal entities that occur 
randomly, so they are transferred from the geographical/temporal space to a unit of a probability interval $(0.1)$. The spatial randomness is introduced through the concepts of random points, lines and polygons while the temporal randomness is introduced through the random dates and random periods. The second one is manifested in geographical/temporal entities that occur in a vague way, so they are transferred from the geographical/temporal space to a unit of a possibility interval. The spatial fuzziness is introduced through the concepts of fuzzy points, lines and polygons, while the temporal fuzziness is introduced through the fuzzy date and the fuzzy period. Despite the detailed study on imperfect data modelling, the imperfect extension of MADS is somewhat lacking. In fact, the reflection generated on the spatial and temporal imperfection does not exceed the theoretical framework. In fact, there is currently no physical response implementing the concepts of random point, random line, random polygon, fuzzy point, fuzzy line, fuzzy polygon, random date, random period, fuzzy date and fuzzy period. Moreover, the possibilistic data modelling is not included in the fuzzy extension of MADS.

The concepts of fuzzy spatiality and fuzzy temporality were also added to the GIS meta-model by Miralles (2006). These concepts have enriched the potential of the imprecision representation in the geographic information systems, notably the perceptory data model. However, in this approach, the author has not considered the implications on the database and on its exploitation through queries that consider the data imprecision. He did not also consider the case of the possibilistic data modelling.

In F-perceptory, we have implemented a set of imprecise spatial and temporal constraints and we have presented a possible application of the approach using imprecise archaeological data.

Table 4 A comparison between the main spatiotemporal modelling methods and our approcach - F-perceptory

\begin{tabular}{|c|c|c|c|c|}
\hline & & Perceptory & Mads & $F$-perceptory \\
\hline \multicolumn{2}{|c|}{ Temporal data types } & Yes & Yes & Yes \\
\hline \multicolumn{2}{|c|}{ Spatial data types } & Yes & Yes & Yes \\
\hline \multirow[t]{3}{*}{$\begin{array}{l}\text { Imperfect } \\
\text { spatial data }\end{array}$} & $\begin{array}{l}\text { Randomness (random } \\
\text { point, line, polygon) }\end{array}$ & No & Yes & No \\
\hline & $\begin{array}{l}\text { Fuzziness (fuzzy } \\
\text { point, line, polygon) }\end{array}$ & Yes & Yes & $\begin{array}{l}\text { Yes + implementation of } \\
\text { fuzzy spatial constraints }\end{array}$ \\
\hline & $\begin{array}{l}\text { Possibility (valued } \\
\text { point, valued line, } \\
\text { valued polygon) }\end{array}$ & No & No & $\begin{array}{c}\text { Yes }+ \text { implementation of } \\
\text { possibilistic spatial } \\
\text { constraints }\end{array}$ \\
\hline \multirow{3}{*}{$\begin{array}{l}\text { Imperfect } \\
\text { temporal } \\
\text { data }\end{array}$} & $\begin{array}{l}\text { Randomness (random } \\
\text { date, random period) }\end{array}$ & No & Yes & No \\
\hline & $\begin{array}{l}\text { Fuzziness (fuzzy date, } \\
\text { fuzzy period) }\end{array}$ & Yes & Yes & $\begin{array}{c}\text { Yes }+ \text { implementation of } \\
\text { fuzzy temporal } \\
\text { constraints }\end{array}$ \\
\hline & $\begin{array}{l}\text { Possibility (valued } \\
\text { date, valued period) }\end{array}$ & No & No & $\begin{array}{c}\text { Yes }+ \text { implementation of } \\
\text { possibilistic spatial } \\
\text { constraints }\end{array}$ \\
\hline \multicolumn{2}{|c|}{ UML compatibility } & Yes & No & Yes \\
\hline
\end{tabular}


We also notice through Table 4, the lack of a UML compatible approach to model and build an information system considering the geographic information in its spatial, temporal and imperfect (particularly imprecise) complexity.

This aspect is considered as the main contribution of F-perceptory.

\section{Conclusions and future work}

In this article, we tackle the issue of modelling geographic information systems that consider information imprecision using an original approach adapted to handle fuzzy and possibilistic spatiotemporal data in class diagrams and, also, in relational/object-oriented databases. The approach enables us to consider two forms of imprecison by assigning them a multivalent representation using the $\alpha$-cuts. Then, we presented an application example of the approach aiming to model and store imprecise spatiotemporal data in a geographic information system. Therefore, we introduced the F-perceptory conceptual data model in which we have defined new pictograms modelling the imprecise space and time. We have also implemented a set of constraints to ensure the data consistency during the transformation process of the fuzzy conceptual model to the spatial database.

In the last section, we proposed a comparative study that highlights our contribution compared to the other fuzzy conceptual models and to the other main spatiotemporal modelling methods. Our approach is distinguished by considering the particularity of spatiotemporal data in fuzzy conceptual data models and by introducing and implementing a set of spatial and temporal constraints required to ensure the data consistency in fuzzy relational and object-oriented databases.

A case tool managing the imprecision and enabling the automation of a spatiotemporal database generation, from the F-perceptory model is currently being implemented. We currently work on the use of our approach for dealing with agronomical data (Zoghlami et al., 2012a). In perspective, we will work on the definition of rules highlighting possible spatiotemporal inconsistencies. These rules aim to avoid spatiotemporal conflicts between geographical objects. We also aim to develop queries that exploit the fuzzy temporal relations (Dubois et al., 2003) and the fuzzy spatial topological relations discussed by Salamat and Zahzah (2012).

\section{References}

Akdag, H., de Glas, M. and Pacholczyk, D. (1992) 'A qualitative theory of uncertainty', Fundamenta Informaticae, Vol. 7, No. 4, pp.333-362.

Bedard, Y. (1999) 'Visual modelling of spatial databases: towards spatial PVL and UML', Geomatica, Vol. 53, No. 2, pp.169-186.

Bédard, Y., Larrivée, S., Proulx, M. and Nadeau, M. (2004) Modeling Geospatial Databases with Plug-Ins for Visual Languages: A Pragmatic Approach and the Impacts of 16 Years of Research and Experimentations on Perceptory, pp.17-30, Springer-Verlag, Shanghai, Chine.

Bejaoui, L., Bédard, Y., Pinet, F. and Schneider, M. (2009) 'Qualified topological relations between spatial objects with possibly vague shape', International Journal of GIS, Vol. 23, No. 7, pp.877-921.

Bosc, P. and Pivert, O. (1995) 'SQLf: a relational database languagefor fuzzy querying', Computer Journal of IEEE Transactions on Fuzzy Systems, Vol. 3, No. 1, pp.80-89. 
Bosc, P. and Pivert, O. (2000) 'SQLf query functionality on top of a regular relational database management', in Pons, O. and Villa, M.A. (Eds.): Knowledge Management in Fuzzy Databases, pp.171-190, Studies in Fuzziness and Soft Computing Series, Springer-Verlag, Heidelbarg.

Bouchon-Meunier, B. (1995) La logique floue et ses Applications, Addison-Wesley, Paris.

Burrough, P. and Frank, A. (Éds.) (1996) Geographic Objects with Indeterminate Boundaries, GISDATA Series éd., Taylor \& Francis, London.

Chen, G. and Kerre, E. (1998) 'Extending ER/EER concepts towards fuzzy conceptual data modeling', IEEE International Conference on Fuzzy Systems, Vol. 2, pp.1320-1325.

Clementini, E. (2005) 'A model for uncertain lines', Journal of Visual Languages \& Computing, Vol. 16, No. 4, pp.271-288.

Clementini, E. and di Felice, P. (1996) 'An algebraic model for spatial objects with indeterminate boundaries', in Burrough, P. and Frank, A. (Éds.): Geographic Objects with Indeterminate Boundaries, pp.155-169, GISData Series éd., Taylor \& Francis, London.

Clementini, E. and di Felice, P. (1997) 'Approximate topological relations', International Journal of Approximate Reasoning, Vol. 16, No. 2, pp.173-204.

Clementini, E. and di Felice, P. (2001) 'A spatial model for complex objects with a broad boundary supporting queries on uncertain data', Data \& Knowledge Engineering, Vol. 37, No. 2, pp. $285-305$.

Cohn, A. and Gotts, N. (1996) 'The 'egg-yolk' representation of regions with indeterminate boundaries', in Burrough, P. and Frank, A. (Éds.): Geographic Objects with Indeterminate Boundaries, GISDATA Series éd., Taylor \& Francis, London.

Desjardin, E. and Pargny, D. (2009) 'GISSAR: Mutualisation des données de chantiers', Conférence Francophone ESRI, Versailles [online] http://www.esrifrance.fr/sig2009/gissarchantiers.htm (accessed 1 April 2014).

Druzdzel, J. (1996) 'Explanation in probabilistic systems: is it feasible? Will it work?', in Proceedings of the Fifth International Workshop on Intelligent Information Systems (WIS-96), Deblin, Poland, s.n., pp.12-24.

Dubois, D., Ali, A.H. and Prade, H. (2003) 'Fuzziness and uncertainty in temporal reasoning', Journal of Universal Computer Science, Vol. 9, No. 9, p.1168-1194.

Erwig, M. and Schneider, M. (1997) 'Vague regions', in Scholl, M. and A. Voisard (Éds.): Advances in Spatial Databases (SSD'97), No. 1262, pp.298-320, Springer, Berlin.

Fisher, P., Comber, A. and Wadsworth, R. (2006) 'Approaches to uncertainty in spatial data', in Devillers, R. and Jeansoulin, R. (Ed.): Fundamentals of Spatial Data Quality, pp.61-88, ISTE, London, UK.

Frank, A. (1998) 'Metamodels for data quality description', in Jeansoulin, R. and Goodchild, M. (Éds.) Data Quality in Geographic Information - From Error to Uncertainty, Hermès, Paris.

Galindo, J., Urrutia, A., Carrasco, R. and Piattini, M. (2004) 'Relaxing constraints in enhanced entity-relationship models using fuzzy quantifiers', IEEE Transactions on Fuzzy Systems, Vol. 12, No. 6, pp.780-796.

Gupta, P., Rishi, R. and Mittal, H. (2011) 'Database design for storage of fuzzy information in traditional database', International Journal of Computer Applications, Vol. 15, No. 2, pp.40-45.

Ma, Z. (2005) 'Fuzzy information modeling with the UML', in Z. Ma (Ed.): Advances in Fuzzy Object-Oriented Databases: Modeling and Applications, pp.153-176, Idea Group Inc., Hershey P.A., USA.

Ma, Z. and Yan, L. (2010) 'A literature overview of fuzzy conceptual data modeling', Journal of Information Science and Engineering, Vol. 26, No. 2, pp.427-441.

Ma, Z., Zhang, W., Ma, W. and Chen, G. (2001) 'Conceptual design of fuzzy object-oriented databases utilizing extended entity-relationship model', International Journal of Intelligent Systems, Vol. 16, No. 6, pp.697-711. 
Miralles, A. (2006) Ingénierie des modéles pour les applications environnementales, s.1.: Phd thesis, Université de Montpellier 2.

Morris, A. and Petry, F.E. (2006) 'UGML: an extension of GMl to provide support for geographic objects with uncertain boundaries', in Spatial Accuracy, pp.794-801, ISARA, Lisbon, s.n.

OMG (2000) OMG Unified Modeling Language Specification, s.1., s.n. [online] http://www.omg.org/spec/UML/1.3/PDF/index.htm (accessed 1 April 2014).

Pantazis, D. (1994) Methodological Analysis for Design and Development of GIS, s.1.: Phd thesis, Université de Liège.

Parent, C. et al. (1997) 'MADS: un modèle conceptuel pour des applications spatio-temporelles', Revue Internationale de Geomatique, Vol. 7, Nos. 3-4, pp.317-352.

Pawlak, P. (1982) 'Rough sets', International Journal of Information and Computer Sciences, Vol. 11, No. 5, pp.341-356.

Piantoni, F. and Pargny, D. (2005) 'Méthodologie pour la gestion, la représentation et la modélisation des données archéologiques', in Conférence Francophone ESRI, Issy-Les-Moulineaux, s.n. [online] http://www.esrifrance.fr/sig2005/communications2005/pargny/pargny.htm (accessed 1 April 2014).

Rodier, X. and Saligny, L. (2007) Modélisation des objets urbains pour l'étude des dynamiques urbaines dans la longue durée. s.l., s.n., in Sageo (2007) [online] http://www.emse.fr/fr/transfert/site/SAGEO2007/CDROM/p34.pdf (accessed 1 April 2014).

Ruspini, E. (1986) 'Imprecision and uncertainty in the entity-relationship model', in Fuzzy Logic in Knowledge Engineering, pp.18-28, Verlag TüV Rhein - land GmbH, Köhn, Germany.

Salamat, N. and Zahzah, E-H. (2012) 'Two-dimensional fuzzy spatial relations: a new way of computing and representation', Advances in Fuzzy Systems, No. 5, Article ID 167939, doi: $10.1155 / 2012 / 167939$.

Sapir, L., Shmilovici, A. and Rokach, L. (2008) 'A methodology for the design of a fuzzy data warehouse', EEE International Conference on Intelligent Systems, Vol. 1, pp.2-14-2-21, Varna, Bulgaria.

Schneider, M. (1996) 'Modelling spatial objects with undetermined boundaries using the realm/ROSE approach', in Burrough, P. and Frank, A. (Éds.): Geographic Objects with Indeterminate Boundaries, GISDATA Series éd., Taylor \& Francis, London.

Schneider, M. (1999) 'Uncertainty management for spatial data in databases: fuzzy spatial data types', Advances in Spatial Databases (SSD'99), Springer, Honk-Kong, pp.330-351.

Shu, H., Spaccapietra, S., Parent, C. and Quesada Sedas, D. (2003) 'Uncertainty of geographic information and its support in MADS', ISSDQ'03 Proceedings, China, s.n, Hong Kong.

Škrbić, S., Racković, M. and Takači, A. (2011) 'Towards the methodology for development of fuzzy relational dtabase applications', Computer Science Information Systems, Vol. 8, No. 1, pp.27-40.

Smets, P. (1996) 'Imperfect information: imprecision and uncertainty', in Uncertainty Management in Information Systems, pp.225-254, s.1.:s.n., Springer, New York, USA.

Tøssebro, E. and Nygård, M. (2002) 'An advanced discrete model for uncertain spatial data', in Third International Conference on Web-Age Information Management, pp.37-51, Springer, Beijing, s.n.

Vandenberghe, R. (1991) 'An extended entity-relationship model for fuzzy databases based on fuzzy truth values', in 4th International Fuzzy Systems Association World Congress, IFSA, Brussels, Belgium, pp.280-283, s.1., s.n.

Vert, G., Stock, M. and Morris, A. (2002) 'Extending ERD modeling notation to fuzzy management of GIS data files', Data and Knowledge Engineering, Vol. 40, No. 2, pp.163-179.

Worboys, M. (1998) 'Imprecision in finite resolution spatial data', GeoInformatica, Vol. 2, No. 3, pp.257-279. 
Worboys, M. and Clementini, E. (2001) 'Integration of imperfect spatial information', Journal of Visual Languages \& Computing, Vol. 12, No. 1, pp.61-80.

Yang, X., We, L., Yu, D. and Yang, J. (2009) 'Rough fuzzy set in incomplete fuzzy information system based on similarity dominance relation', Recent Patents on Computer Science, Vol. 2, No. 1, pp.68-74.

Zadeh, L. (1965) 'Fuzzy sets', Information and Control, Vol. 8, No. 3, pp.338-353.

Zoghlami, A. (2013) Modélisation et conception de systèmes d'information géographique gérant l'imprécision, $\mathrm{PhD}$ thesis, Université Paris 8, Saint-Denis.

Zoghlami, A., de Runz, C., Akdag, H. and Pargny, D. (2012) 'Through a fuzzy spatiotemporal information system for handling excavation data', in Agile 2012, Springer, Avignon, France, s.n., pp.179-196.

Zoghlami, A., Zayrit, K., de Runz, C., Desjardin, E. and Akdag, A. (2012) 'Vers la construction d'un observatoire des pratiques agricoles: gestion et propagation de l'imprécision des données agronomiques', in EGC 2012, Hermann, Bordeaux, France, pp.537-542.

Zvieli, A. and Chen, P. (1986) 'Entity-relationship modeling and fuzzy databases', in IEEE International Conference on Data Engineering, pp.320-327, IEEE, Los Angeles, California, s.n. 